\title{
The Oxygen Reduction Reaction on Graphene from Quantum Mechanics: Comparing Armchair and Zigzag Carbon Edges
}

Quang Ly, Boris V. Merinov, Hai Xiao, William A. Goddard, and Ted Yu

J. Phys. Chem. C, Just Accepted Manuscript • DOI: 10.1021/acs.jpcc.7b07405 • Publication Date (Web): 10 Oct 2017

Downloaded from http://pubs.acs.org on October 10, 2017

\section{Just Accepted}

"Just Accepted" manuscripts have been peer-reviewed and accepted for publication. They are posted online prior to technical editing, formatting for publication and author proofing. The American Chemical Society provides "Just Accepted" as a free service to the research community to expedite the dissemination of scientific material as soon as possible after acceptance. "Just Accepted" manuscripts appear in full in PDF format accompanied by an HTML abstract. "Just Accepted" manuscripts have been fully peer reviewed, but should not be considered the official version of record. They are accessible to all readers and citable by the Digital Object Identifier (DOI®). "Just Accepted" is an optional service offered to authors. Therefore, the "Just Accepted" Web site may not include all articles that will be published in the journal. After a manuscript is technically edited and formatted, it will be removed from the "Just Accepted" Web site and published as an ASAP article. Note that technical editing may introduce minor changes to the manuscript text and/or graphics which could affect content, and all legal disclaimers and ethical guidelines that apply to the journal pertain. ACS cannot be held responsible for errors or consequences arising from the use of information contained in these "Just Accepted" manuscripts. 
The Oxygen Reduction Reaction on Graphene from Quantum Mechanics: Comparing Armchair and Zigzag Carbon Edges

\author{
Quang Ly, ${ }^{1}$ Boris V. Merinov, ${ }^{2}$ Hai Xiao ${ }^{2}$, William A. Goddard III, ${ }^{2}$ Ted H. Yu ${ }^{1,2^{*}}$ \\ ${ }^{1}$ Department of Chemical Engineering, California State University, Long Beach, California, \\ 1250 Bellflower Blvd, Long Beach California, 92840, USA. \\ ${ }^{2}$ Materials and Process Simulation Center, California Institute of Technology, 1200 East \\ California Blvd., M/C 139-74, Pasadena, California 91125, USA
}

\begin{abstract}
Using density functional theory (PBE-D2 flavor), we report the mechanism for the oxygen reduction reaction (ORR) on graphene sheets. We find that ORR starts with OO chemisorbing onto the carbon edges, rather than the basal plane face, which is not energetically favorable. The carbon edges were described as one-dimensional periodic graphene ribbons with both armchair and zigzag edges. We calculated the binding energies of the ORR products $(\mathrm{OO}, \mathrm{OOH}, \mathrm{O}, \mathrm{OH}, \mathrm{HOH}, \mathrm{HOOH})$ for the zigzag and armchair edges, examining both the Langmuir Hinshelwood (LH) and Eley-Rideal (ER), to understand how $\mathrm{OO}$ is reduced. For the armchair edge, we calculate an onset potential of $0.55 \mathrm{~V}$ vs. Reversible Hydrogen Electrode (RHE), which corresponds to $-0.22 \mathrm{~V}$ at $\mathrm{pH} 13$ in agreement with experiments. We find that the rate-determining step (RDS) to form peroxide (a $2 \mathrm{e}^{-}$ process) is hydrogenation of adsorbed $\mathrm{OO}$ with a barrier of $0.92 \mathrm{eV}$. The process to make water (a $4 \mathrm{e}^{-}$process) was found to be unfavorable at the onset potential but becomes more favorable at lower potentials. Thus, undoped carbon catalysts prefer the $2 \mathrm{e}^{-}$mechanism to form peroxide, rather than the $4 \mathrm{e}^{-}$process to form water, which agrees with experiment. The
\end{abstract}


predictions open the route for experimental studies to improve the sluggish ORR on carbon catalysts.

\section{Introduction}

Proton exchange membrane fuel cells, also known as polymer electrolyte membrane fuel cells (PEMFCs), show great promises for clean energy technology. The PEMFC allows HH and $\mathrm{OO}$ gas to react electrochemically to produce power with only water and heat as byproducts (not pollutants or greenhouses gases as emitted by traditional engines). The ratedetermining process in PEMFCs is the oxygen reduction reaction (ORR), combining protons from the anode with $\mathrm{OO}$ to form water. Platinum or platinum-based catalysts show the highest ORR performance, making them the standard catalyst. However, the high cost of platinum motivates the search for alternative materials with similar or better performance ${ }^{1-2}$.

Carbon based catalysts ${ }^{2}$ would be attractive but the ORR performance is not yet adequate. In order to learn how to improve the catalytic performance, we undertake here a quantum mechanics (QM) based study to understand the mechanism by which the un-doped carbon catalyst forms peroxide and not water. The un-doped carbon ORR catalysis has also been consistently shown to lead to catalysis at the carbon edges or defects and not basal planes ${ }^{2-4}$. Experiments observe that selective doping (N, S, Fe, Br, Cl, and I) of the carbon catalyst can improve activity and change the mechanism from the undesirable $2 \mathrm{e}^{-}$product of hydrogen peroxide $e^{2,5-6}$ to the desirable $4 \mathrm{e}^{-}$product, water ${ }^{2,6}$. A number of ORR mechanisms have been proposed by experimentalists and theorists to explain these results for doped carbon catalysts, but there is no consensus on the reaction intermediates and catalyst sites. Addition of Fe improves ORR performance in acidic environment ${ }^{7}$, but the role of the transition metals in the ORR mechanism is not clear. There are reports of improved performance in the absence of metal doping ${ }^{2,8-9}$, but this could be due to metal impurities in the synthesis process. The $\mathrm{Fe}_{3} \mathrm{~N}$ group has been shown to be the site of $4 \mathrm{e}^{-}$catalysis ${ }^{10}$ for a specific case, but many Fe- 
N-C catalysts do not contain this specific group. QM studies have considered Fe on the basal plane as the catalytic center ${ }^{11-12}$, which has been confirmed experimentally ${ }^{13}$. However, FeN-C catalysts with extremely low Fe concentration still performed well in acidic conditions ${ }^{2}$, 14. Thus, there remains an incomplete picture of the catalytic mechanism, although it is clear that adding metals does facilitate ORR in an acid environment.

Theoretical studies of nitrogen-doped catalysts without $\mathrm{Fe}^{15-19}$ report that these catalysts are less acid tolerant ${ }^{2}$ and that $4 \mathrm{e}^{-}$ORR selectivity depends on nitrogen edge sites (pyridinic $^{20}$, pyrollic, or graphitic ${ }^{21}$ ). Most QM studies of ORR are on doped-carbon, with few QM studies on how doping facilitates the changes that transform the ORR mechanism from the $2 \mathrm{e}^{-}$to $4 \mathrm{e}^{-}$. Indeed, many studies do not even consider the $2 \mathrm{e}^{-}$mechanism.

To make a progress in this area, it is important to determine the detailed ORR mechanism on undoped carbon catalysts, to serve as a foundation towards understanding ORR on doped carbon catalysts. The basal plane ${ }^{22}$, armchair and zigzag sites have very different binding properties. A literature search on the active site of undoped carbon ORR is inconclusive as mechanisms of armchair and zigzag edges exist in literature. It was shown that the initial OO adsorption step is more energetically favorable on undoped zigzag edges ${ }^{23}$, and the entire ORR mechanism for zigzag was proposed with DFT simulations ${ }^{24}$. On the other hand, carbon ORR catalysis was proposed to occur on the armchair edge ${ }^{25-27}$, based on experimental studies reporting the $2 \mathrm{e}^{-}$ORR on chemically similar quinone. ${ }^{28-29}$ Based on the Tafel slopes, two mechanisms were proposed for glassy carbon ${ }^{30}$ and pyrolytic graphite ${ }^{3}$ ORR catalysts by Yeager and coworkers,

Glassy carbon: $\quad \mathrm{OO} \rightarrow \mathrm{OO}(\mathrm{ads})$;

$$
\begin{aligned}
& \mathrm{OO}(\mathrm{ads})+\mathrm{e}-\rightarrow[\mathrm{OO}(\mathrm{ads})]^{-} ; \\
& {[\mathrm{OO}(\mathrm{ads})]^{-} \rightarrow \mathrm{OO}(\mathrm{ads}) ;} \\
& \mathrm{OO}(\mathrm{ads})^{-}+\mathrm{HOH} \rightarrow \mathrm{OOH}(\mathrm{ads})+\mathrm{OH}^{-} ;
\end{aligned}
$$




$$
\mathrm{OOH}(\mathrm{ads})^{-} \rightarrow \mathrm{OOH}^{-}
$$

Pyrolytic graphite: $\quad \mathrm{OO} \rightarrow \mathrm{OO}(\mathrm{ads})$;

$$
\begin{aligned}
& \mathrm{OO}(\mathrm{ads})+\mathrm{HOH}+\mathrm{e}-\rightarrow \mathrm{OOH}(\mathrm{ads})+\mathrm{OH}^{-} \\
& 2 \mathrm{OOH}(\text { ads })+\mathrm{OH}^{-} \rightarrow \mathrm{OOH}^{-}+\mathrm{OO}+\mathrm{HOH}
\end{aligned}
$$

Both peroxide forming mechanisms start with $\mathrm{OO} \rightarrow \mathrm{OO}$ (ads) as the first step. Experimental results indicate that reaction (4) was rate limiting for glassy carbon and reaction (8) was rate limiting for pyrolytic graphite. It turns out both of these steps are the first hydrogenation step. However, this mechanisms although reasonable, has not been proved ${ }^{25}$. The aim of this work is to provide conclusive evidence for the site and mechanism of the ORR on un-doped carbon catalysts with quantum mechanics.

\section{Computational Details}

Periodic quantum mechanics (QM) calculations were carried out using SeqQUEST $\operatorname{code}^{31}$, which employs Gaussian basis functions at the optimized double- $\zeta$ plus polarization level rather than the plane wave basis often used in periodic systems. We used the PerdewBecke-Ernzerhof (PBE) flavour ${ }^{32}$ of DFT in the generalized gradient approximation (GGA) ${ }^{33}$ with Grimme's semi-empirical van der Waals corrections and allowed the up-spin orbitals to be optimized independently of the down-spin orbitals (spin unrestricted DFT). The small core pseudopotentials with angular momentum projections ${ }^{34}$ are applied in our calculations. Two models of $5 \times 4$ graphene are used. One has armchair edges with a cell of $16.2 \AA \times 37.0 \AA \times$ $26.5 \AA$, while the other has zigzag edges with a cell of $9.8 \AA \times 38.2 \AA \times 26.5 \AA$. The edge is terminated with hydrogen atoms. The model is periodic in one-dimension along edge without $\mathrm{H}$ atoms, which is the shortest. The structure was optimized from a 2-dimensional graphene calculation. 
The nudged elastic band (NEB) approach ${ }^{35},{ }^{16}$ in SeqQUEST was applied to find the minimum energy paths and reaction transition states to obtain the activation barriers for all intermediate steps. Five images were examined for each intermediate step to identify the transition state. The coordinates for all NEB calculations are in Supplemental Information (SI). Barriers involving $\mathrm{H}$ addition were calculated in two ways: Langmuir Hinshelwood (LH) and Eley-Rideal (ER) barriers. The LH barrier is the energy that needs to be surmounted in order to add $\mathrm{H}$ when it is already adsorbed on the catalyst surface (Figure 1a). These barriers are potential independent ${ }^{36-37}$.

The ER barrier is the energy needed to add $\mathrm{H}$ when it originates from the solution. The method to determine the ER potential dependent barriers follows the method previously applied for $\mathrm{CO}_{2}$ reduction ${ }^{38-39}$. For ORR, the entire mechanism was partitioned into two or four intermediate steps depending on the final product, peroxide or water. Each intermediate step has an addition of one hydrogen through water in the solution (Figure 1b, c). For each of these intermediate steps, the starting and ending points are oxygen-containing species (abbreviated below as " $\mathrm{X}$ ”) before and after hydrogenation:

$$
\begin{aligned}
& \text { Reaction: } \mathrm{X}+\mathbf{H O H}+\mathrm{e}^{-} \rightarrow \mathrm{XH}+\mathrm{OH}^{-} \\
& \text {Starting point: } \mathrm{X}+\mathbf{H O H}+H \\
& \text { Ending Point: } \mathrm{XH}+\mathrm{HOH}
\end{aligned}
$$

$\mathrm{X}=(\mathrm{OO}, \mathrm{OOH}, \mathrm{O}$, or $\mathrm{OH})$, and the bolded $\mathbf{H}$ shuttles through the $\mathrm{HOH}$ from the italicized $H$, as the source of the hydrogen in an alkaline environment. Based on the standard hydrogen electrode (SHE) reference $\mathrm{H}^{+}+\mathrm{e}^{-} \rightarrow 1 / 2 \mathrm{HH},{ }^{40}$ the energy of $\mathrm{OH}^{-}$is determined from DFT calculations using the equivalency: $\mathrm{E}_{\mathrm{OH}^{-}}=\mathrm{E}_{\mathrm{HOH}}-\mathrm{E}_{\mathrm{H}^{+}}=\mathrm{E}_{\mathrm{HOH}}-1 / 2 \mathrm{E}_{\mathrm{HH}}$. After this substitution, the onset potential, $\mathrm{V}_{\text {onset}}$, for an intermediate reaction in alkaline solution, $\mathrm{V}_{\text {onset }}$ $=\mathrm{E}_{\mathrm{HOH}}+\mathrm{E}_{\mathrm{X}}-\mathrm{E}_{\mathrm{XH}}-\mathrm{E}_{\mathrm{OH}^{-}}$simplifies to $\mathrm{V}_{\text {onset }}=1 / 2 \mathrm{E}_{\mathrm{HH}}+\mathrm{E}_{\mathrm{X}}-\mathrm{E}_{\mathrm{XH}}$, where onset potential voltage is the negative of the energy difference of reactants and products of reaction (10). 
The negative sign is from the Nernst equation, $\Delta \mathrm{G}=-\mathrm{nFE}$, which describes the onset potential voltage, $\mathrm{E}$, as positive when the free energy of the reaction, $\Delta \mathrm{G}$, is negative. The overall onset potential is the minimum onset potential of all intermediate reactions ${ }^{40}$. When onset potential is taken into account with activation barrier, transition state energy, $\mathrm{E}_{\mathrm{TS}}(\mathrm{U})$, is the sum of the activation barrier obtained from NEB DFT calculations of $\mathrm{E}_{\mathrm{TS}}{ }^{0}$ with an effective symmetry factor $(\beta)$ of onset potential $(U)$, where $0<\beta<1$.

$$
\mathrm{E}_{\mathrm{TS}}(\mathrm{U})=\mathrm{E}_{\mathrm{TS}}^{0}+\beta \mathrm{U}
$$

As shown in Figure 2, the simplest approximation sets the symmetry factor to be 0.5 , with an assumption of a perfectly symmetric reactions ${ }^{38}$. Other methods to approximate the symmetry factor by using charge or Fermi energy have also been described ${ }^{38,41-42} . \beta$ can also be estimated using the $\mathrm{O}-\mathrm{H}$ bond length to approximate charge transfer, as demonstrated below.

\section{$\underline{\text { 3. Results and Discussions }}$}

\subsection{Binding Energies:}

The various ORR intermediates $(\mathrm{H}, \mathrm{O}, \mathrm{OH}, \mathrm{OO}, \mathrm{OOH}, \mathrm{HOH}, \mathrm{HOOH})$ were attached to the zigzag and armchair graphene (Gr) edges, but many sites have unfavorable negative binding energy (BE) or they detach. The BEs and sites of binding are shown in Figures 3 and 4. The $\mathrm{BE}$ of species $\mathrm{X}$ is defined by the equation:

$$
B E_{-X}=E_{G r}+E_{X}-E_{G r-X}
$$

Analyzing the $\mathrm{BEs}$, we see that $\mathrm{H}, \mathrm{O}$, and $\mathrm{OH}$ groups bind exothermically with the $\mathrm{H}$ and $\mathrm{OH}$ prefer binding in a 1-fold positions, while $\mathrm{O}$ prefers to bind in a 2-fold position.

For $\mathrm{OO}$ and $\mathrm{OOH}$, the binding is favorable only at the edges, as previously reported for $\mathrm{OO}^{43}$. Binding $\mathrm{OO}$ on the basal plane is uphill by $\sim 2 \mathrm{eV}$. This explains why carbon catalysis occurs at the edge and not on the basal planes. ${ }^{2}$ Some previous studies did not 
consider whether $\mathrm{OO}$ binds to the catalyst surface. ${ }^{19}$ In all cases, the preferred binding position is at the edge site on the carbon also bound to an $\mathrm{H}$ atom.

- For $\mathrm{OOH}$, the binding site for zigzag is Position 1 (Figure 4) with a binding energy of $1.70 \mathrm{eV}$ while for armchair it is Position 1 (see Figure 3) with a binding energy of 0.23 $\mathrm{eV}$.

- For OO, the binding site for zigzag is Position 1 with binding energy of $0.44 \mathrm{eV}$ (Figure 4), while that for armchair is 2-fold position 1-2 (Figure 3), which is slightly endothermic $(-0.23 \mathrm{eV})^{43}$. The armchair edge $\mathrm{OO}$ binding site can be a local energy minima as long as the barrier to approach this site is low, which we will show.

- The $\mathrm{HOH}$ and $\mathrm{HOOH}$ species do not bind to any sites, even at the edges.

We calculated the reaction path for OO approaching the armchair binding site by fixing/increasing the $\mathrm{C}-\mathrm{O}$ distance between the edge carbon and oxygen from the equilibrium distance of $1.48 \AA$, while relaxing all other atoms (see Figure 5). The triplet is preferred for long $\mathrm{C}-\mathrm{O}$ distances, with a transition state barrier of $0.70 \mathrm{eV}$ at $\mathrm{C}-\mathrm{O}=1.86 \AA$. (Note that the artificial energy well between $3.5 \AA$ and $6 \AA$ due to basis set superposition.) The barrier for OO to approach the carbon basal plane is much higher, $2.5 \mathrm{eV}$.

Binding $\mathrm{H}, \mathrm{OOH}$, or $\mathrm{OH}$ leads to a doublet state, since a pi bond is attacked. However, the two upaired spins for $\mathrm{O}$ and $\mathrm{OO}$ both bind to obtain a spin that is singlet. The only exception is for end-on OO binding on the zigzag site, which prefers the spin of triplet.

Starting with hydrogen bound to the preferred armchair edge Position 1 site with a binding energy of $1.80 \mathrm{eV}$, we analysed the energy to bind to a $2^{\text {nd }} \mathrm{H}$ to a nearby carbon. Figure 3 shows the energy of the second hydrogen binding to the ortho, meta, and para sites. We see that the ortho (1-2) sites are favorable leading to a spin singlet. The most favorable ortho binding site is on the edge with a binding energy of $3.45 \mathrm{eV}$. For all cases except $\mathrm{O}$, the binding energy of the zigzag edge is stronger than that of the armchair edge by 
approximately $1.5 \mathrm{eV}$. Table 1 compares the BEs of the most favorable sites of $\mathrm{O}, \mathrm{OH}, \mathrm{OOH}$, $\mathrm{OO}$, and $\mathrm{H}$ with those for $\mathrm{Pt}$ and $\mathrm{Pt}_{3} \mathrm{Ni}^{44}$.

\subsection{Adsorbed Species Langmuir-Hinshelwood Reactions:}

We calculated LH reaction barriers to determine the reaction pathway for ORR. This is needed for direct catalyst degradation experiments, as performed by Ghassamedeh et $\mathrm{al}^{45-46}$ where both $\mathrm{HH}$ and $\mathrm{OO}$ are present in large quantities. It provides a simpler method of calculating ORR barriers, easily comparable with calculations for other catalysts ${ }^{36,47-49}$.

Although the binding of two $\mathrm{H}$ atoms is strongest at site (1-2), the barriers for reactions ending or starting with adjacent atoms was found to be unfavorable. Thus, we used the para sites for adding hydrogen and OO dissociation. The transition state for each step was determined by starting with the lowest energy configuration of the reactant and exploring all the convenient pathways toward the product. The path with the lowest barrier decides the reaction mechanism. Based on Figure 6 and Table 2, seven individual barriers were examined:

1) OO dissociation: $(\mathrm{OO})_{\mathrm{ad}} \rightarrow \mathrm{O}_{\mathrm{ad}}+\mathrm{O}_{\mathrm{ad}}$

2) OOH formation: $(\mathrm{OO})_{\mathrm{ad}}+\mathrm{H}_{\mathrm{ad}} \rightarrow(\mathrm{OOH})_{\mathrm{ad}}$

3) OOH dehydration: $(\mathrm{OOH})_{\mathrm{ad}}+\mathrm{H}_{\mathrm{ad}} \rightarrow \mathrm{O}_{\mathrm{ad}}+\mathrm{HOH}$

4) OH formation: $\mathrm{O}_{\mathrm{ad}}+\mathrm{H}_{\mathrm{ad}} \rightarrow(\mathrm{OH})_{\mathrm{ad}}$

5) HOOH formation: $(\mathrm{OOH})_{\mathrm{ad}}+\mathrm{H}_{\mathrm{ad}} \rightarrow \mathrm{HOOH}$

6) OOH hydration: $(\mathrm{OOH})_{\mathrm{ad}}+\mathrm{HOH} \rightarrow \mathrm{HOOH}+(\mathrm{OH})_{\mathrm{ad}}$

7) HOH formation: $(\mathrm{OH})_{\mathrm{ad}}+\mathrm{H}_{\mathrm{ad}} \rightarrow \mathrm{HOH}$

Table 2 shows the barriers to be overcome for the seven intermediate steps, leading to the reaction pathways for zigzag and armchair and their rate determining steps (RDS). In both armchair and zigzag edges, water formation (the $4 \mathrm{e}^{-}$pathway) follows the path: $\mathrm{OOH}$ formation $\rightarrow \mathrm{OOH}$ dehydration $\rightarrow \mathrm{OH}$ formation $\rightarrow \mathrm{HOH}$ formation. 
The RDS of water formation for armchair corresponds to the $\mathrm{OH}$ formation step which has a value of $1.32 \mathrm{eV}$, while that for zigzag is $\mathrm{OOH}$ dehydration with a barrier of $1.07 \mathrm{eV}$. The pathway for peroxide formation (the $2 \mathrm{e}^{-}$pathway) follows the path: $\mathrm{OOH}$ formation $\rightarrow$ $\mathrm{HOOH}$ formation for both armchair and zigzag edges. $\mathrm{HOOH}$ formation is the RDS for both edges.

Table 3 summarizes the possible reaction pathways and their RDS. These results suggest that the zigzag edge is easier for the reactions to occur. Both armchair and zigzag edges prefer the peroxide formation. In the environment where both $\mathrm{HH}$ and $\mathrm{OO}$ are plentiful, we predict that the zigzag edge is more active for ORR with a RDS of $0.11 \mathrm{eV}$ vs. the armchair RDS which is $0.73 \mathrm{eV}$ for producing peroxide.

\subsection{Potential Dependent Eley-Rideal Reactions:}

The first step to study the ER barriers is to determine the ORR onset potentials ${ }^{38-40}$ of the intermediate reactions in ORR as seen in Table 4. Using this method, we take the lowest onset potential for each path as the predicted onset potential. For the armchair edge, the predicted onset potential for both $4 \mathrm{e}^{-}$and $2 \mathrm{e}^{-}$pathways is $0.55 \mathrm{~V}$ at $\mathrm{pH} 0 \mathrm{vs}$. RHE, which converts to $-0.22 \mathrm{~V}$ at $\mathrm{pH} 13$ in excellent agreement with experimental results of graphene referencing the reversible hydrogen electrode ${ }^{15}$ (RHE) of $-0.14 \mathrm{~V}$. A similar experiment for graphene using $\mathrm{Ag} / \mathrm{AgCl}$ reference electrode ${ }^{50}$ found onset potential $-0.41 \mathrm{~V}$ at $\mathrm{pH} 13$, which converts to $-0.24 \mathrm{~V}$ for RHE close to our result of $-0.22 \mathrm{~V}$. For the zigzag edge, the predicted onset potential for $2 \mathrm{e}^{-}$pathway is $-0.97 \mathrm{~V}$ at $\mathrm{pH} 13 \mathrm{vs}$. RHE. The zigzag edge is not able to produce peroxide at the higher potential due to the much stronger binding energy of $\mathrm{OOH}$.

We found that for the armchair edge, the onset potential is insufficient to predict whether the $2 \mathrm{e}^{-}$or $4 \mathrm{e}^{-}$reaction is preferred, because both reactions have the same onset potential due to the same initial hydrogenation step that occurs for both reactions. Although this first step is avoided by starting with $\mathrm{OO}$ dissociation $^{36}$, the barrier is too high at $1.45 \mathrm{eV}$ 
(Table 2). In order to predict the favorable product, the potential dependent ER barriers need to be calculated. We looked at the barrier of a hydrogen transferring by shuttling through a water molecule, rather than from an adsorbed hydrogen on the carbon surface, and compared the rate determining barrier for the $2 \mathrm{e}^{-}$and $4 \mathrm{e}^{-}$reaction. This is very convenient computationally, since the water molecule does not adsorb on the edges and lies just on top of the reactants. First, we assumed symmetric reaction which makes symmetry factor, $\beta=0.5$ (or charge transfer coefficient, $\alpha)^{3,38}$ as seen in Figures 7 and 8 . These barriers are considered at $\mathrm{pH} 0$ where $\mathrm{HH}$ is equivalent in energy with $\mathrm{H}^{+}$for RHE. The energy of $\mathrm{OH}^{-}$is calculated by the equation: $\mathrm{E}_{\mathrm{OH}^{-}}=\mathrm{E}_{\mathrm{HOH}}-1 / 2 \mathrm{E}_{\mathrm{HH}}$. We find the highest barrier for the $4 \mathrm{e}^{-}$ pathway at onset potential of $0.55 \mathrm{~V}$ (corresponding to $-0.22 \mathrm{~V}$ at $\mathrm{pH} 13$ ) to be $\mathrm{OOH}$ dehydration with a barrier of $1.46 \mathrm{eV}$. For the $2 \mathrm{e}^{-}$pathway reaction, it is the $\mathrm{OOH}$ formation barrier of $0.94 \mathrm{eV}$, also at the onset potential of $0.55 \mathrm{~V}$. We find that the $2 \mathrm{e}^{-}$pathway is favorable, in excellent agreement with experiments showing that peroxide formation is dominant in carbon type catalysts at the onset potential. ${ }^{5-6}$

\subsection{Determining the Symmetry Factor}

Assuming the reaction symmetry factor $\beta^{38}$ to be 0.5 is a simple way to measure the potential-dependent barriers. Accurate methods are needed to calculate $\beta$. There are several methods described in literature ${ }^{38,41-42}$. With some of these schemes, an assumption was made that the electron enters the electrode system in a fractional manner as $\mathrm{H}$ approaches O. First, we looked at using DFT calculated Mulliken charges ${ }^{42}$ to determine reaction symmetry factor. However, the Mulliken charge results for the intermediate ORR reactions were not consistent (see Table 5). In some cases, the charge of the transition state did not lie between those of initial state and final state, which incorrectly implied the reaction symmetry factor to be less than 0 or greater than 1 . Another limitation is shown in Table 5, where we see that the Mulliken charges vary from 0.09 to 0.50 , and do not represent a full electron transfer. It 
would be convenient to find a method where the change in charge from the initial state to final state represents a one electron difference.

Table 5 also reports the results of determining the reaction symmetry factor using the calculated bond order. During each ORR intermediate step at the cathode, a single, new O-H bond forms between the reducing hydrogen and an oxygen from $\mathrm{OO}, \mathrm{OOH}, \mathrm{O}$, or $\mathrm{OH}$. An electron travels from the fuel cell anode, through the circuit to the cathode surface to form this bond as seen in Figure 9. The degree of charge transfer for this bond is characterized by its bond order. We used the bond distance to calculate the bond order using ReaxFF parameters fitted from QM calculations ${ }^{51-52}$. The previously optimized parameters are: $\mathrm{p}_{\mathrm{bo}, 1}$ $=-0.0778, \mathrm{p}_{\mathrm{bo}, 1}=4.3082, \mathrm{r}_{\mathrm{o}}=0.9093$. The $\mathrm{OH}$ bond order equation based on bond length is:

$$
\text { OH Bond Order }=\exp \left[p_{b o, 1}\left(\frac{\text { OH Bond Length }}{r_{o}}\right)^{p_{b o, 2}}\right]
$$

As bond distance increases, the corresponding bond order decreases and vice versa. The benefit of this method is that there is no need to use the initial and final states of the reaction as a reference, because the bond order only depends on the $\mathrm{O}-\mathrm{H}$ length. The bond order is zero at the initial state when the hydrogen is far away and nearly one $(0.91)$ after the new O$\mathrm{H}$ bond is formed based on equation 22. For other methods, the charges or the Fermi energy of the initial and final geometry needs to be referenced to see where the quantity lies at the transition state in relation with the initial and final. For this new proposed method, an $\mathrm{O}-\mathrm{H}$ bond length at the transition state is the one data used without the need to reference other DFT data.

The ER potential dependent barriers using the bond order method to calculate $\beta$ are reported in Table 6 . We only consider armchair edge as the zigzag edge onset potential is too low. The table shows the barriers at $0 \mathrm{~V}$ and the onset potential at $0.55 \mathrm{~V}$. We determined the barriers for all ORR intermediates. For the $2 \mathrm{e}^{-}$reaction, $\mathrm{OOH}$ formation was found to be the RDS at $0.55 \mathrm{~V}$ with a barrier of $0.92 \mathrm{eV}$. For the $4 \mathrm{e}^{-}$reaction, $\mathrm{OOH}$ dehydration was found 
to be the RDS at $0.55 \mathrm{~V}$ with a barrier of $1.35 \mathrm{eV}$. The $2 \mathrm{e}^{-}$reaction is more favorable, which agrees with literature results. ${ }^{3-4,25}$ Figures 10 and 11 also show the Nørskov diagrams including ER barriers for the $2 \mathrm{e}^{-}$and $4 \mathrm{e}^{-}$mechanisms at $0 \mathrm{~V}$ and $0.55 \mathrm{~V}$. For the 2emechanism, the RDS has a predicted symmetry factor, $\beta$, of 0.46 which is close to experimental values of 0.5 for ORR on pyrolytic graphite ${ }^{3}$.

\subsection{Water Formation at Low Potentials}

Experiments with rotating ring desk electrode (RRDE) ${ }^{15,53}$ have shown that water formation does occur at low potentials resulting in electron transfer greater than 2 . The reaction to reduce peroxide was: $\mathrm{HOOH}+\mathbf{H O H}+\mathrm{e}^{-} \rightarrow(\mathrm{OH})_{\mathrm{ad}}+\mathrm{HOH}+\mathrm{OH}^{-}$which is followed by reduction of $\mathrm{OH}:(\mathrm{OH})_{\mathrm{ad}}+\mathbf{H O H}+\mathrm{e}^{-} \rightarrow \mathrm{HOH}+\mathrm{OH}^{-}$. This alternative mechanism to form water from dioxygen via peroxide is shown in Table 4 and 6, and can occur on both zigzag and armchair edges. The barrier for the reduction of armchair edge at the onset potential of $0.55 \mathrm{~V}$ is $0.77 \mathrm{eV}$ (Table 6). It is lower than the RDS barrier of $0.92 \mathrm{eV}$ for the $2 \mathrm{e}^{-} \mathrm{ORR}$ reaction. However, once the armchair edge site is occupied, it will be difficult for the peroxide reaction to occur. The competing reactions for $2 \mathrm{e}^{-}$vs. $4 \mathrm{e}^{-}$ORR to occur are the adsorption of $\mathrm{OO}$, which has a barrier of $0.70 \mathrm{eV}$ (Figure 5), and peroxide reduction. As the potential decreases, the barrier for reducing peroxide will be lower than that of $\mathrm{OO}$ adsorption which is not potential dependent. Figure 12 shows that at higher potential, the armchair site only converts OO to peroxide, because the barrier for peroxide reduction is higher than $0.77 \mathrm{eV}$. As the potential lowers below $0.32 \mathrm{~V}$, the armchair sites also converts peroxide to water. Figure 13 represents the Nørskov diagrams and barriers for the $4 \mathrm{e}^{-}$mechanism via peroxide formation for armchair edge at $0 \mathrm{~V}$ and $0.32 \mathrm{~V}$. The RDS for this reaction at $0.32 \mathrm{~V}$ is equal to $0.70 \mathrm{eV}$. This is much lower than the RDS for the direct $4 \mathrm{e}^{-}$ mechanism which is $1.32 \mathrm{eV}$ at $0.32 \mathrm{~V}$.

\subsection{Strategies to Improve ORR}


The RDS for ORR at the armchair edge is $0.92 \mathrm{eV}$ at $0.55 \mathrm{~V}$, which is for the first hydrogenation reaction $\left(\mathrm{Gr}-\mathrm{OO}+\mathbf{H O H}+\mathrm{e}^{-} \rightarrow \mathrm{Gr}-\mathrm{OOH}+\mathrm{OH}^{-}\right)$, as previously proposed ${ }^{3,30}$. This barrier is moderately high, corresponding to the sluggish ORR observed in undoped carbon catalyst ${ }^{5-6}$. In order to improve this barrier, the reaction needs to be more exothermic. This is difficult as the $\mathrm{OO}$ and $\mathrm{OOH}$ binding energies tend to be correlated ${ }^{40,54}$, which means increasing one will increase the other. However, binding energy correlation is more a trend than a rule, so there is possible room for improvement ${ }^{55-56}$. For graphene, a possible strategy is to dope it with a single atom that gives a doublet spin, such as column III or V elements on the periodic table. This is because the unpaired spin in $\mathrm{OOH}$ can pair with an unpaired doublet to form an energetically favourable singlet, while OO cannot. Spin pairing results in a much stronger bond for $\mathrm{OOH}$ than for $\mathrm{OO}$, which will lower the barrier for this reaction.

\section{$\underline{\text { 4. Conclusion }}$}

Using QM, we studied the ORR on carbon edge sites terminated with hydrogen. The binding energies of the zigzag edge tend to be stronger than those of the armchair edge. The binding energies for the zigzag carbon edges are usually higher than those for $\mathrm{Pt}$ and $\mathrm{Pt}_{3} \mathrm{Ni}$, while those for the armchair edge are lower. We find that the ORR activity is inactive on the basal planes because both $\mathrm{OO}$ and $\mathrm{OOH}$ only bind on the edges, in agreement with experiments $^{3-4}$.

In the LH model where hydrogen is absorbed on the carbon, we find that peroxide formation is a favored process. For this model, the zigzag edges have a lower RDS of 0.09 $\mathrm{eV}$ than armchair edges which is $0.86 \mathrm{eV}$. The $\mathrm{RDS}$ for both sites is attributed to $\mathrm{H}+$ $(\mathrm{OOH})_{\mathrm{ad}} \rightarrow \mathrm{HOOH}$, which is lower than the RDS to form water. However, this is only for the experiments with $\mathrm{HH}$ and $\mathrm{OO}$ simultaneously present, such as degradation experiments.

In the ER model, we first determined the ORR onset potential, which was found for the armchair edge to be $0.55 \mathrm{~V}$ at $\mathrm{pH} 0$ corresponding to $-0.22 \mathrm{~V}$ at $\mathrm{pH} 13$ vs. RHE. This is 
consistent with experiments for ORR on graphene catalysts. ${ }^{6,15,50}$ The onset potential for the zigzag edges was lower for both peroxide and water formation, due to the strong binding energy of both $\mathrm{OOH}$ and $\mathrm{OH}$. The armchair onset potential of $0.55 \mathrm{~V}$ alone was insufficient to determine whether the $2 \mathrm{e}^{-}$or $4 \mathrm{e}^{-}$mechanism is favored, because it is identical for both mechanisms. With just the binding energy result and Nørskov diagrams without barriers, we can, however, predict that the armchair is the active carbon edge for the ORR on this type of catalysts. The armchair active site is similar to catalyst site of quinone, which has been shown in experiments to undergo $2 \mathrm{e}^{-} \mathrm{ORR}$.

With the onset potential of $0.55 \mathrm{~V}$, the ER barriers were calculated for both the $2 \mathrm{e}^{-}$and $4 \mathrm{e}^{-}$ mechanisms. We developed a simple way to calculate the barriers using the bond order to estimate the reaction symmetry factor, $\beta$. We compared the results with the method of assuming $\beta$ to be 0.5 . The $2 \mathrm{e}^{-}$mechanism has a RDS of $0.92 \mathrm{eV}$, while the $4 \mathrm{e}^{-}$mechanism has a RDS barrier of $1.35 \mathrm{eV}$. These are in qualitative agreement with experimental results indicating that peroxide formation is a favorable process. Including barriers in this calculation was necessary since the binding energies alone could not prove which product (peroxide or water) was favorable.

The ORR starts with OO approaching the armchair edge with a barrier of $0.70 \mathrm{eV}$. The RDS for the electron transfer process is $0.92 \mathrm{eV}$ which corresponds to the first hydrogenation step to form $(\mathrm{OOH})_{\mathrm{ad}}$ in agreement with experimentally proposed mechanisms ${ }^{25}$. The $(\mathrm{OOH})_{\mathrm{ad}}$ can either form $\mathrm{HOOH}$ via hydrogenation or $\mathrm{O}_{\mathrm{ad}}$ via hydrogenation/dehydration. The latter has a higher barrier of $1.35 \mathrm{eV}$. The $4 \mathrm{e}^{-}$mechanism can continue with $\mathrm{O}_{\mathrm{ad}}$ from hydrogenation to form $(\mathrm{OH})_{\mathrm{ad}}$ then $\mathrm{HOH}$. An alternative pathway for the $4 \mathrm{e}^{-}$mechanism involves $\mathrm{HOOH}$ reduction via hydrogenation/dehydration to form $(\mathrm{OH})_{\mathrm{ad}}$, then hydrogenation to form $\mathrm{HOH}$. Forming water via peroxide has a lower barrier of $0.77 \mathrm{eV}$ than the direct water formation. However, peroxide has to compete against $\mathrm{OO}$ for the armchair edge site. 
At high potentials, the $\mathrm{OO}$ is dominant on armchair edge sites because the barrier to bind is lower at $0.70 \mathrm{eV}$. At low potentials $(<0.32 \mathrm{~V})$, the peroxide reduction barrier decreases to less than $0.70 \mathrm{eV}$, which makes water formation just as favorable. This mechanism explains why $4 \mathrm{e}^{-}$ORR can occur at lower potentials in experiments. The $\mathrm{RDS}$ of $0.92 \mathrm{eV}$ is moderately high, in agreement with the sluggishness of ORR reported for undoped carbon catalysts.

Supporting Information:

Initial, final, and optimized image geometries for all NEB barrier calculations.

Author information:

Corresponding Author

ted.yu@csulb.edu

\section{$\underline{\text { Acknowledgment }}$}

This research was supported by the National Institute of General Medical Sciences of the National Institutes of Health under Award Numbers; 8UL1GM118979-02; 8TL4GM11898002; 8RL5GM118978-02 and NSF grant CBET-1512759 (B.V.M., H.X. and W.A.G.). The content is solely the responsibility of the authors and does not necessarily represent the official views of the National Institutes of Health. This work is supported by the grants of CSULB Office of Research and Sponsored Program (ORSP) Grant, RSCA Faculty Small Grant, CSULB Start Up Grant, and Southern California Air Quality Management District Grant (T.H.Y.).

\section{$\underline{\text { References }}$}

1. $\quad$ Ross, P. N.; Markovic, N. M., Doe Annual Hydrogen Review 2004.

2. Zhang, J.; Xia, Z.; Dai, L., Carbon-Based Electrocatalysts for Advanced Energy Conversion and Storage. Sci. Adv. 2015, 1, e1500564.

3. Morcos, I.; Yeager, E., Kinetic Studies of the Oxygen-Peroxide Couple on Pyrolytic Graphite. Electrochim Acta 1970, 1, 953-975.

4. Song, C.; Zhang, J., Electrocatalytic Oxygen Reduction Reaction. In Pem Fuel Cell Electrodecatalysts and Catalyst Layers Fundamentals and Applications, Zhang, J., Ed. Springer: 2008; Vol. XXI, pp 89-134. 
5. Malkhandi, S.; Trinh, P.; Manohar, A. K.; Jayachandrababu, K. C.; Kindler, A.; Prakash, G. K.; Narayanan, S. R., Electrocatalytic Activity of Transition Metal Oxide-Carbon Composites for Oxygen Reduction in Alkaline Batteries and Fuel Cells. J Electrochem Soc 2013, 160, F943-F952.

6. Jeon, I. Y., et al., Facile, Scalable Synthesis of Edge-Halogenated Graphene Nanoplatelets as Efficient Metal-Free Electrocatalysts for Oxygen Reduction Reaction. Scientific Reports 2013, 3, 1-7.

7. Shui, J.; Chen, C.; Grabstanowicz, L.; Zhao, D.; Liu, D. J., Highly Efficient Nonprecious Metal Catalyst Prepared with Metal-Organic Framework in a Continuous Carbon Nanofibrous Network. P Natl Acad Sci USA 2015, 112, 10629-10634.

8. $\quad$ Li, Y.; Wu, Z.; Wang, H.; Xie, L.; Liang, Y.; Wei, F.; Idrobo, J. C.; Pennycook, S. J.; Dai, H., An Oxygen Reduction Electrocatalyst Based on Carbon Nanotube-Graphene Complexes. Nature Nanotechnology 2012, 7, 394-400.

9. Yu, D.; Zhang, Q.; Dai, L., Highly Efficient Metal-Free Growth of Nitrogen-Doped Single-Walled Carbon Nanotubes on Plasma-Etched Substrates for Oxygen Reduction. $J$ Am Chem Soc 2010, 132, 15127-15129.

10. Qian, Y.; Du, P.; Wu, P.; Cai, C.; Gervasio, D. F., Chemical Nature of Catalytic Active Sites for the Oxygen Reduction Reaction on Nitrogen-Doped Carbon-Supported NonNoble Metal Catalysts. J Phys Chem C 2016, 120, 9884-9896.

11. Liang, W.; Chen, J.; Liu, Y.; Chen, S., Density-Functional-Theory Calculation Analysis of Active Sites for Four-Electron Reduction of $\mathrm{O} 2$ on Fe/N-Doped Graphene. Acs Catalysis 2014, 4, 4170-4177.

12. Cheng, M. J.; Head-Gordon, M.; Bell, A. T., How to Chemically Tailor MetalPorphyrin-Like Active Sites on Carbon Nanotubes and Graphene for Minimal Overpotential in the Electrochemical Oxygen Evolution and Oxygen Reduction Reactions. J Phys Chem C 2014, 118, 29482-29491.

13. Zitolo, A.; Goellner, V.; Armel, V.; Sougrati, M.; Mineva, T.; Lorenzo, S.; Fonda, E.; Jaouen, F., Identification of Catalytic Sites for Oxygen Reduction in Iron- and NitrogenDoped Graphene Materials. Nat Mater 2016, 14, 937-944.

14. Zhang, L.; Niu, J.; Dai, L.; Xia, Z., Effect of Microstructure of Nitrogen-Doped Graphene on Oxygen Reduction Activity in Fuel Cells. Langmuir 2012, 28, 7542-7550.

15. Jiao, Y.; Zheng, Y.; Jaroniec, M.; Qiao, S. Z., Origin of the Electrocatalytic Oxygen Reduction Activity of Graphene-Based Catalysts: A Roadmap to Achieve the Best Performance. J Am Chem Soc 2014, 136, 4394-4403.

16. Yu, L.; Pan, X.; Cao, X.; Hu, P.; Bao, X., Oxygen Reduction Reaction Mechanism on Nitrogen-Doped Graphene: A Density Functional Theory Study. J Catal 2011, 282, 183-190.

17. Sidik, R. A.; Anderson, A. B.; Subramanian, N. P.; Kumaraguru, S. P.; Popov, B. N., O2 Reduction on Graphite and Nitrogen-Doped Graphite: Experiment and Theory. J. Phys. Chem. B 2006, 110, 1787-1793.

18. Zhang, Y. H.; Duan, Z. Y.; Xiao, C.; Wang, G. F., Density Functional Theory Calculation of Platinum Surface Segregation Energy in Pt(3)Ni (111) Surface Doped with a Third Transition Metal. Surf Sci 2011, 605, 1577-1582.

19. Zhang, L.; Xia, Z., Mechanisms of Oxygen Reduction Reaction on Nitrogen-Doped Graphene for Fuel Cells. J Phys Chem C 2011, 115, 11170-11176.

20. Xing, T.; Zheng, Y.; Li, L. H.; Cowie, B. C. C.; Gunzelmann, D.; Qiao, S. Z.; Huang, S. L.; Chen, Y., Observation of Active Sites for Oxygen Reduction Reaction on NitrogenDoped Multilayer Graphene. ACS Nano 2014, 8, 6856-6862.

21. Liu, R. G.; Wu, D.; Feng, X.; Mullen, K., Nitrogen-Doped Ordered Mesoporous Graphitic Arrays with High Electrocatalytic Activity for Oxygen Reduction. Angew Chem Int Edit 2010, 49, 2565-2569. 
22. Hughes, Z. E.; Walsh, T. R., Computational Chemistry for Graphene-Based Energy Applications: Progress and Challenges. Nanoscale 2015, 7, 6883-6908.

23. Ikeda, T.; Boero, M.; Huang, S. F.; Terakura, K.; Ohshima, M.; Ozaki, J. I., Carbon Alloy Catalysts: Active Sites for Oxygen Reduction Reaction. Journal of Physical Chemistry C Letters 2008, 112, 14706-14709.

24. Ikeda, T.; Hou, Z.; Chai, G. L.; Terakura, K., Possible Oxygen Reduction Reactions for Graphene Edges from First Principles. J Phys Chem C 2014, 118, 17616-17625.

25. Yeager, E., Dioxygen Electrocatalysis: Mechanisms in Relation to Catalyst Structure. J Mol Catal a-Chem 1986, 38, 5-25.

26. Garten, V. A.; Weiss, D. E., Rev. Pure Appl. Chem. 1957, 7, 69.

27. Garten, V. A.; Weiss, D. E., Austr. J. Chem. 1955, 8, 81.

28. Vaik, K.; Sarapuu, A.; Tammeveski, K.; Mimrkhalaf, F.; Schiffrin, D. J., Oxygen Reduction on Phenanthrenequinone-Modified Glassy Carbon Electrode in $0.1 \mathrm{M}$ Koh. $J$ Electroanal Chem 2004, 564, 159-66.

29. Tissot, P.; Huissoud, A., Electrochemical Reduction of 2-Ethyl-9,10-Anthraquinone (Eaq) and Mediated Formation of Hydrogen Peroxide in a Two-Phase Medium. Journal of Applied Electrochemistry 1999, 29, 11-25.

30. Zhang, Z. W.; Tryk, D.; Yeager, E. The Electrochemical Society, National Meeting, Washington, Washington, 1983; p Abst. 394.

31. Schultz, P. Seqquest, Sandia National Laboratory. dft.sandia.gov/Quest/.

32. Perdew, J. P.; Burke, K.; Ernzerhof, M., Generalized Gradient Approximation Made Simple. Phys Rev Lett 1996, 77, 3865-3868.

33. Ceperley, D. M.; Alder, B. J., Ground-State of the Electron-Gas by a Stochastic Method. Phys Rev Lett 1980, 45, 566-569.

34. Melius, C. F.; Goddard, W. A., Ab-Initio Effective Potentials for Use in Molecular Quantum-Mechanics. Phys Rev A 1974, 10, 1528-1540.

35. Mills, G.; Jonsson, H., Quantum and Thermal Effects in H-2 Dissociative Adsorption - Evaluation of Free-Energy Barriers in Multidimensional Quantum-Systems. Phys Rev Lett 1994, 72, 1124-1127.

36. Yu, T. H.; Sha, Y.; Merinov, B. V.; Goddard, W. A., Improved Non-Pt Alloys for the Oxygen Reduction Reaction at Fuel Cell Cathodes Predicted from Quantum Mechanics. $J$ Phys Chem C 2010, 114, 11527-11533.

37. Tsai, H. C.; Hsieh, Y. C.; Yu, T. H.; Lee, Y. J.; Wu, Y. H.; Merinov, B. V.; Wu, P. W.; Chen, S. Y.; Adzic, R. R.; Goddard, W. A., Dft Study of Oxygen Reduction Reaction on Os/Pt Core-Shell Catalysts Validated by Electrochemical Experiments. Acs Catalysis 2015, 5, 1568-1580.

38. Nie, X.; M.R., E.; Janik, M. J.; Asthagiri, A., Selectivity of Co2 Reduction on Copper Electrodes: The Role of the Kinetics of Elementary Steps. Angew Chem Int Edit 2013, 52, 2459-2462.

39. Xiao, H.; Cheng, T.; Goddard, W. A.; Sundararaman, R., Mechanistic Explanation of the $\mathrm{Ph}$ Dependence and Onset Potentials for Hydrocarbon Products from Electrochemical Reduction of Co on $\mathrm{Cu}$ (111). J Am Chem Soc 2016, 138, 483-486.

40. Nørskov, J. K.; Rossmeisl, J.; Logadottir, A.; Lindqvist, L.; Kitchin, J. R.; Bligaard, T.; Jonsson, H., Origin of the Overpotential for Oxygen Reduction at a Fuel-Cell Cathode. $J$ Phys Chem B 2004, 108, 17886-17892.

41. Cheng, T.; Xiao, H.; Goddard, W. A., Free-Energy Barriers and Reaction Mechanisms for the Electrochemical Reduction of $\mathrm{Co}$ on the $\mathrm{Cu}(100)$ Surface, Including Multiple Layers of Explicit Solvent at Ph 0. Journal of Physical Chemistry Letters 2015, 6, 4767-4773. 
42. Chan, K.; Nørskov, J. K., Electrochemical Barriers Made Simple. Journal of Physical Chemistry Letters 2015, 6, 2663-2668.

43. Kim, H.; Lee, K.; Woo, S. H.; Jung, Y., On the Mechanism of Enhanced Oxygen Reduction Reaction in Nitrogen-Doped Graphene Nanoribbons. Phys. Chem. Chem. Phys. 2011, 13, 17505-17510.

44. Sha, Y.; Yu, T. H.; Merinov, B.; Shirvanian, P.; Goddard, W. A., Mechanism for Oxygen Reduction Reaction on Pt3ni Alloy Fuel Cell Cathode. J Phys Chem C 2012, 116, 21334-21342.

45. Ghassemzadeh, L.; Kreuer, K. D.; Maier, J.; Muller, K., Chemical Degradation of Nation Membranes under Mimic Fuel Cell Conditions as Investigated by Solid-State Nmr Spectroscopy. J Phys Chem C 2010, 114, 14635-14645.

46. Yu, T. H.; Sha, Y.; Liu, W. G.; Merinov, B. V.; Shirvanian, P.; Goddard, W. A., Mechanism for Degradation of Nafion in Pem Fuel Cells from Quantum Mechanics Calculations. J Am Chem Soc 2011, 133, 19857-19863.

47. Jacob, T.; Goddard, W. A., Water Formation on Pt and Pt-Based Alloys: A Theoretical Description of a Catalytic Reaction. Chemphyschem 2006, 7, 992-1005.

48. Tsai, H. C.; Yu, T. H.; Sha, Y.; Merinov, B.; Wu, P. W.; Chen, S. Y.; Goddard, W. A., Density Functional Theory Study of Pt3m Alloy Surface Segregation with Adsorbed $\mathrm{O} / \mathrm{Oh}$ and Pt3os as Catalysts for Oxygen Reduction Reaction. J Phys Chem C 2014, 118, 26703-26712.

49. Sha, Y.; Yu, T. H.; Merinov, B.; Shirvanian, P.; Goddard, W. A., Oxygen Hydration Mechanism for the Oxygen Reduction Reaction at Pt and Pd Fuel Cell Catalysts. Journal of Physical Chemistry Letters 2011, 2, 572-576.

50. Qu, L.; Liu, Y.; Baek, J. B.; Dai, L., Nitrogen-Doped Graphene as Efficient MetalFree Electrocatalyst for Oxygen Reduction in Fuel Cells. ACS Nano 2010, 4, 1321-1326.

51. van Duin, A. C. T.; Dasgupta, S.; Lorant, F.; Goddard, W. A., Reaxff: A Reactive Force Field for Hydrocarbons. J Phys Chem A 2001, 105, 9396-9409.

52. Van Duin, A. C. T.; Zou, C.; Joshi, K.; Bryantsev, V.; Goddard, W. A., A Reaxff Reactive Force-Field for Proton Transfer Reactions in Bulk Water and Its Applications to Heterogeneous Catalysis; RSC Publishing: Cambridge, UK, 2012; Vol. 14.

53. Jurmann, G.; Tammeveski, K., Electroreduction of Oxygen on Multi-Walled Carbon Nanotube Modified Highly Oriented Pyrolytic Graphite Electrodes in Alkaline Solution. $J$ Electroanal Chem 2006, 597, 26.

54. Yu, T. H.; Hofmann, T.; Sha, Y.; Merinov, B.; Myers, D. J.; Heske, C.; Goddard, W. A., Finding Correlations of the Oxygen Reduction Reaction Activity of Transition Metal Catalysts with Parameters Obtained from Quantum Mechanics. J Phys Chem C 2013, 2659826607.

55. Xin, H.; Linic, S., Exceptions to the D-Band Model of Chemisorption on Metal Surfaces: The Dominant Role of Repulsion between Adsorbate States and Metal D-States. $J$. Chem. Phys. 2010, 132, 221101-221104.

56. Yu, T. H.; Torres, R.; Merinov, B.; Goddard, W. A., Elucidating Challenges of Reactions with Correlated Reactant and Product Binding Energies on an Example of Oxygen Reduction Reaction. J Mol Catal a-Chem 2016, 423, 449-456.

Table 1. Comparison between armchair edge, zigzag edge, $\mathrm{Pt}_{3} \mathrm{Ni}^{44}$ (111), and $\mathrm{Pt}(111)$ binding energies.

\begin{tabular}{|l|c|c|c|c|}
\hline Intermediates & Armchair & Zigzag & $\mathbf{P t}_{\mathbf{3}} \mathbf{N i}$ & $\mathbf{P t}$ \\
\hline $\mathrm{H}(\mathrm{eV})$ & 1.80 & 3.28 & 2.70 & 2.80 \\
\hline
\end{tabular}




\begin{tabular}{|l|c|c|c|c|}
\hline $\mathrm{OH}(\mathrm{eV})$ & 1.73 & 3.20 & 2.42 & 2.28 \\
\hline $\mathrm{OOH}(\mathrm{eV})$ & 0.23 & 1.70 & 1.05 & 1.06 \\
\hline $\mathrm{OO}(\mathrm{eV})$ & -0.23 & 0.44 & 0.59 & 0.46 \\
\hline $\mathrm{O}(\mathrm{eV})$ & 3.13 & 2.81 & 3.47 & 3.66 \\
\hline
\end{tabular}

Table 2. LH barriers for intermediate steps in the ORR.

\begin{tabular}{|c|c|c|c|}
\hline \multirow[t]{2}{*}{ Step } & \multirow[t]{2}{*}{ Barrier } & \multicolumn{2}{|c|}{ Edge Type } \\
\hline & & $\begin{array}{l}\text { Armchair } \\
(\mathrm{eV})\end{array}$ & $\begin{array}{c}\text { Zigzag } \\
(\mathrm{eV})\end{array}$ \\
\hline 1 & $\begin{array}{c}\text { OO } \\
\text { Dissociation }\end{array}$ & 1.45 & 1.15 \\
\hline 2 & $\begin{array}{c}\mathrm{OOH} \\
\text { Formation }\end{array}$ & 0.51 & 0.02 \\
\hline 3 & $\begin{array}{c}\mathrm{OOH} \\
\text { Dehydration }\end{array}$ & 0.49 & 1.07 \\
\hline 4 & $\begin{array}{c}\mathrm{OH} \\
\text { Formation }\end{array}$ & 1.32 & 0.11 \\
\hline 5 & $\begin{array}{c}\text { HOOH } \\
\text { Formation }\end{array}$ & 0.86 & 0.09 \\
\hline 6 & $\begin{array}{c}\mathrm{OOH} \\
\text { Hydration }\end{array}$ & 0.45 & 1.19 \\
\hline 7 & $\begin{array}{c}\mathrm{HOH} \\
\text { Formation }\end{array}$ & 0.84 & 0.80 \\
\hline
\end{tabular}

Table 3. LH reaction pathways and RDS between armchair and zigzag edges.

\begin{tabular}{|l|l|l|l|}
\hline $\begin{array}{l}\text { Edge } \\
\text { type }\end{array}$ & Formation & $\begin{array}{l}\text { Pathway } \\
\text { order }\end{array}$ & RDS \\
\hline Armchair & Water & $2,3,4,7$ & $(4)=1.32 \mathrm{eV}$ \\
\cline { 2 - 4 } & Peroxide & 2,5 & $(5)=0.86 \mathrm{eV}$ \\
\hline \multirow{2}{*}{ Zigzag } & Water & $2,3,4,7$ & $(3)=1.07 \mathrm{eV}$ \\
\cline { 2 - 4 } & Peroxide & 2,5 & $(5)=0.09 \mathrm{eV}$ \\
\hline
\end{tabular}

Table 4. Calculated onset potentials for the $2 \mathrm{e}^{-}$and $4 \mathrm{e}^{-}$reactions on both zigzag and armchair edges.

\begin{tabular}{|c|c|c|c|}
\hline \multirow{2}{*}{$\begin{array}{c}\text { Onset } \\
\text { Potential }\end{array}$} & \multicolumn{2}{|c|}{ Intermediate Step } & \multicolumn{2}{|c|}{ Onset Potential (V) } \\
\cline { 3 - 4 } & & Zigzag & Armchair \\
\hline $\begin{array}{c}2 \mathrm{e}^{-} \mathrm{ORR} \text { to } \\
\text { form } \\
\text { peroxide: }\end{array}$ & $1)(\mathrm{OO})_{\mathrm{ad}}+\mathbf{H O H}+\mathrm{e}^{-} \rightarrow(\mathrm{OOH})_{\mathrm{ad}}+\mathrm{OH}^{-}$ & 1.34 & 0.55 \\
\cline { 2 - 4 } & $2)(\mathrm{OOH})_{\mathrm{ad}}+\mathbf{H O H}+\mathrm{e}^{-} \rightarrow \mathrm{HOOH}+\mathrm{OH}^{-}$ & -0.21 & 1.32 \\
\cline { 2 - 4 } & Overall Onset Potential & $\mathbf{- 0 . 2 1}$ & $\mathbf{0 . 5 5}$ \\
\hline $4 \mathrm{e}^{-}$ORR to & $1)(\mathrm{OO})_{\mathrm{ad}}+\mathbf{H O H}+\mathrm{e}^{-} \rightarrow(\mathrm{OOH})_{\mathrm{ad}}+\mathrm{OH}^{-}$ & 1.34 & 0.55 \\
\hline
\end{tabular}




\begin{tabular}{|c|c|c|c|}
\hline \multirow[t]{4}{*}{ form water: } & 2) $(\mathrm{OOH})_{\mathrm{ad}}+\mathbf{H O H}+\mathrm{e}^{-} \rightarrow \mathrm{O}_{\mathrm{ad}}+\mathbf{H O H}+\mathrm{OH}$ & 0.89 & 2.68 \\
\hline & 3) $\mathrm{O}_{\mathrm{ad}}+\mathbf{H O H}+\mathrm{e}^{-} \rightarrow(\mathrm{OH})_{\mathrm{ad}}+\mathrm{OH}^{-}$ & 2.50 & 0.72 \\
\hline & 4) $(\mathrm{OH})_{\mathrm{ad}}+\mathbf{H O H}+\mathrm{e}^{-} \rightarrow \mathrm{HOH}+\mathrm{OH}^{-}$ & 0.07 & 1.55 \\
\hline & Overall Onset Potential & 0.07 & 0.55 \\
\hline \multirow{5}{*}{$\begin{array}{c}4 \mathrm{e}^{-} \text {ORR to } \\
\text { form water } \\
\text { via } \\
\text { peroxide: }\end{array}$} & 1) $(\mathrm{OO})_{\mathrm{ad}}+\mathbf{H O H}+\mathrm{e}^{-} \rightarrow(\mathrm{OOH})_{\mathrm{ad}}+\mathrm{OH}^{-}$ & 1.34 & 0.55 \\
\hline & 2) $(\mathrm{OOH})_{\mathrm{ad}}+\mathbf{H O H}+\mathrm{e}^{-} \rightarrow \mathrm{HOOH}+\mathrm{OH}^{-}$ & -0.21 & 1.32 \\
\hline & $\begin{array}{l}\text { 3) } \mathrm{HOOH}+\mathbf{H O H}+\mathrm{e}^{-} \rightarrow(\mathrm{OH})_{\mathrm{ad}}+\mathrm{HOH}+ \\
\mathrm{OH}^{-}\end{array}$ & 3.60 & 2.08 \\
\hline & 4) $(\mathrm{OH})_{\mathrm{ad}}+\mathbf{H O H}+\mathrm{e}^{-} \rightarrow \mathrm{HOH}+\mathrm{OH}^{-}$ & 0.07 & 1.55 \\
\hline & Overall Onset Potential & -0.21 & 0.55 \\
\hline
\end{tabular}

Table 5. Comparison between charge analysis and bond order methods to obtain effective symmetry factor $(\beta)$.

\begin{tabular}{|c|c|c|c|c|c|c|c|}
\hline \multirow[b]{2}{*}{ Steps } & & \multicolumn{4}{|c|}{ Charge Analysis } & \multicolumn{2}{|c|}{ Bond Order } \\
\hline & & $\underline{\text { Initial }}$ & $\underline{\mathrm{TS}}$ & Final & $\underline{\beta}$ & $\frac{\text { Bond Length }}{(\AA)}$ & $\underline{\beta}$ \\
\hline \multirow{2}{*}{$\begin{array}{c}(\mathrm{OO})_{\mathrm{ad}}+\mathbf{H O H}+\mathrm{e}^{-} \rightarrow \\
(\mathrm{OOH})_{\mathrm{ad}}+\mathrm{OH}^{-}\end{array}$} & $\mathrm{O}$ & -0.286 & -0.614 & -0.371 & $\mathrm{~N} / \mathrm{A}$ & \multirow{2}{*}{1.61} & \multirow{2}{*}{0.41} \\
\hline & $\mathrm{H}$ & 0.427 & 0.443 & 0.409 & $\mathrm{~N} / \mathrm{A}$ & & \\
\hline \multirow{2}{*}{$\begin{array}{c}(\mathrm{OOH})_{\mathrm{ad}}+\mathbf{H O H}+\mathrm{e}^{-} \rightarrow \\
\mathrm{O}_{\mathrm{ad}}+\mathrm{HOH}+\mathrm{OH}^{-}\end{array}$} & $\mathrm{O}$ & -0.385 & -0.642 & -0.828 & 0.580 & \multirow{2}{*}{1.73} & \multirow{2}{*}{0.29} \\
\hline & $\mathrm{H}$ & 0.432 & 0.453 & 0.434 & $\mathrm{~N} / \mathrm{A}$ & & \\
\hline \multirow{2}{*}{$\begin{array}{c}(\mathrm{OOH})_{\mathrm{ad}}+\mathbf{H O H}+\mathrm{e}^{-} \rightarrow \\
\mathrm{HOOH}+\mathrm{OH}^{-}\end{array}$} & $\mathrm{O}$ & -0.386 & -0.446 & -0.471 & 0.708 & \multirow{2}{*}{1.28} & \multirow{2}{*}{0.71} \\
\hline & $\mathrm{H}$ & 0.447 & 0.455 & 0.484 & 0.207 & & \\
\hline \multirow{2}{*}{$\begin{array}{c}\mathrm{O}_{\mathrm{ad}}+\mathbf{H O H}+\mathrm{e}^{-} \rightarrow(\mathrm{OH})_{\mathrm{ad}} \\
+\mathrm{OH}^{-}\end{array}$} & $\mathrm{O}$ & -0.582 & -0.702 & -0.676 & $\mathrm{~N} / \mathrm{A}$ & \multirow{2}{*}{1.48} & \multirow{2}{*}{0.53} \\
\hline & $\mathrm{H}$ & 0.425 & 0.482 & 0.404 & $\mathrm{~N} / \mathrm{A}$ & & \\
\hline \multirow{2}{*}{$\begin{array}{c}(\mathrm{OH})_{\mathrm{ad}}+\mathbf{H O H}+\mathrm{e}^{-} \rightarrow \\
\mathrm{HOH}+\mathrm{OH}^{-}\end{array}$} & $\mathrm{O}$ & -0.732 & -0.764 & -0.824 & 0.353 & \multirow{2}{*}{1.20} & \multirow{2}{*}{0.77} \\
\hline & $\mathrm{H}$ & 0.433 & 0.458 & 0.424 & $\mathrm{~N} / \mathrm{A}$ & & \\
\hline
\end{tabular}

Table 6: ER Barriers of armchair edge using bond order to calculate symmetry factor.

\begin{tabular}{|c|c|c|c|c|}
\hline \multirow{2}{*}{$\begin{array}{c}\text { ORR } \\
\text { pathway }\end{array}$} & Intermediate Step & $\begin{array}{c}\text { Symmetry } \\
\text { Factor, } \beta\end{array}$ & $\begin{array}{c}\text { ER Barrier } \\
\text { at } 0 \mathrm{~V}(\mathrm{eV})\end{array}$ & $\begin{array}{c}\text { ER Barrier } \\
\text { at 0.55 V } \\
(\mathrm{eV})\end{array}$ \\
\hline $\begin{array}{c}2 \mathrm{e}^{-} \mathrm{ORR} \\
\text { to form } \\
\text { peroxide: }\end{array}$ & $1)(\mathrm{OO})_{\mathrm{ad}}+\mathbf{H O H}+\mathrm{e}^{-} \rightarrow(\mathrm{OOH})_{\mathrm{ad}}+\mathrm{OH}^{-}$ & 0.46 & 0.67 & 0.92 \\
\cline { 2 - 5 } & $2)(\mathrm{OOH})_{\mathrm{ad}}+\mathbf{H O H}+\mathrm{e}^{-} \rightarrow \mathrm{HOOH}+\mathrm{OH}^{-}$ & 0.71 & 0 & 0.31 \\
\hline $4 \mathrm{e}^{-} \mathrm{ORR}$ & $1)(\mathrm{OO})_{\mathrm{ad}}+\mathbf{H O H}+\mathrm{e}^{-} \rightarrow(\mathrm{OOH})_{\mathrm{ad}}+\mathrm{OH}^{-}$ & 0.46 & 0.67 & 0.92 \\
\hline
\end{tabular}




\begin{tabular}{|c|c|c|c|c|}
\hline \multirow[t]{4}{*}{$\begin{array}{l}\text { to form } \\
\text { water: }\end{array}$} & 2) $\begin{array}{c}(\mathrm{OOH})_{\mathrm{ad}}+\underset{\mathrm{OH}^{-}}{\mathbf{H O H}+\mathrm{e}^{-}} \rightarrow \mathrm{O}_{\mathrm{ad}}+\mathrm{HOH}+ \\
.\end{array}$ & 0.29 & 1.20 & 1.35 \\
\hline & 3) $\mathrm{O}_{\mathrm{ad}}+\mathbf{H O H}+\mathrm{e}^{-} \rightarrow(\mathrm{OH})_{\mathrm{ad}}+\mathrm{OH}^{-}$ & 0.53 & 0.80 & 1.09 \\
\hline & 4) $(\mathrm{OH})_{\mathrm{ad}}+\mathbf{H O H}+\mathrm{e}^{-} \rightarrow \mathrm{HOH}+\mathrm{OH}^{-}$ & 0.40 & 0 & 0.21 \\
\hline & RDS & 0.29 & 1.20 & 1.35 \\
\hline \multirow{5}{*}{$\begin{array}{l}4 \mathrm{e}^{-} \text {ORR } \\
\text { to form } \\
\text { water via } \\
\text { peroxide: }\end{array}$} & 1) $(\mathrm{OO})_{\mathrm{ad}}+\mathbf{H O H}+\mathrm{e}^{-} \rightarrow(\mathrm{OOH})_{\mathrm{ad}}+\mathrm{OH}^{-}$ & 0.46 & 0.67 & 0.92 \\
\hline & 2) $(\mathrm{OOH})_{\mathrm{ad}}+\mathbf{H O H}+\mathrm{e}^{-} \rightarrow \mathrm{HOOH}+\mathrm{OH}^{-}$ & 0.71 & 0.07 & 0.31 \\
\hline & 3) $\begin{aligned} \mathrm{HOOH}+\mathbf{H O H} & +\mathrm{e}^{-} \rightarrow(\mathrm{OH})_{\mathrm{ad}}+\mathrm{HOH} \\
& +\mathrm{OH}^{-}\end{aligned}$ & 0.32 & 0.60 & 0.77 \\
\hline & 4) $(\mathrm{OH})_{\mathrm{ad}}+\mathbf{H O H}+\mathrm{e}^{-} \rightarrow \mathrm{HOH}+\mathrm{OH}^{-}$ & 0.40 & 0 & 0.21 \\
\hline & RDS & 0.46 & 0.67 & 0.92 \\
\hline
\end{tabular}

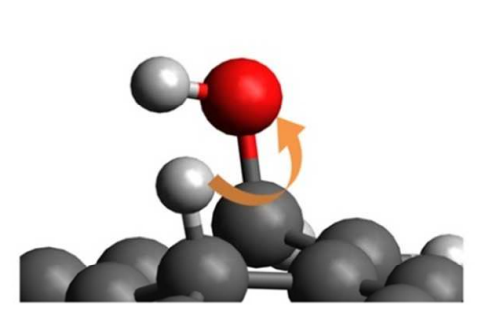

Figure 1 (a) Without water assist

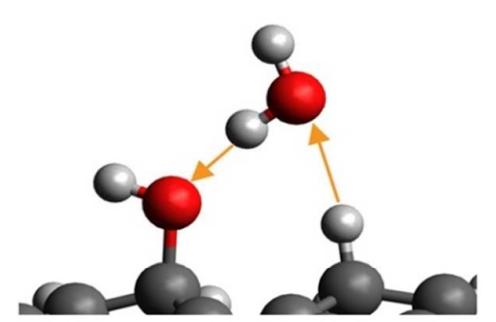

Figure 1 (b) One water assist

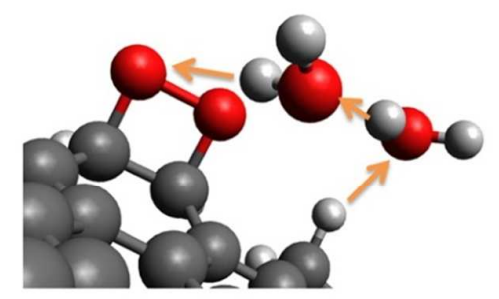

Figure 1 (c) Two water assist

Figure 1. (a) Model for LH reactions with $\mathrm{H}$ adsorbed from the surface. (b) Model for ER reactions with $\mathrm{H}$ shuttling through one water to simulate an alkaline environment. (c) Model for ER reactions with $\mathrm{H}$ shuttling through two waters. 


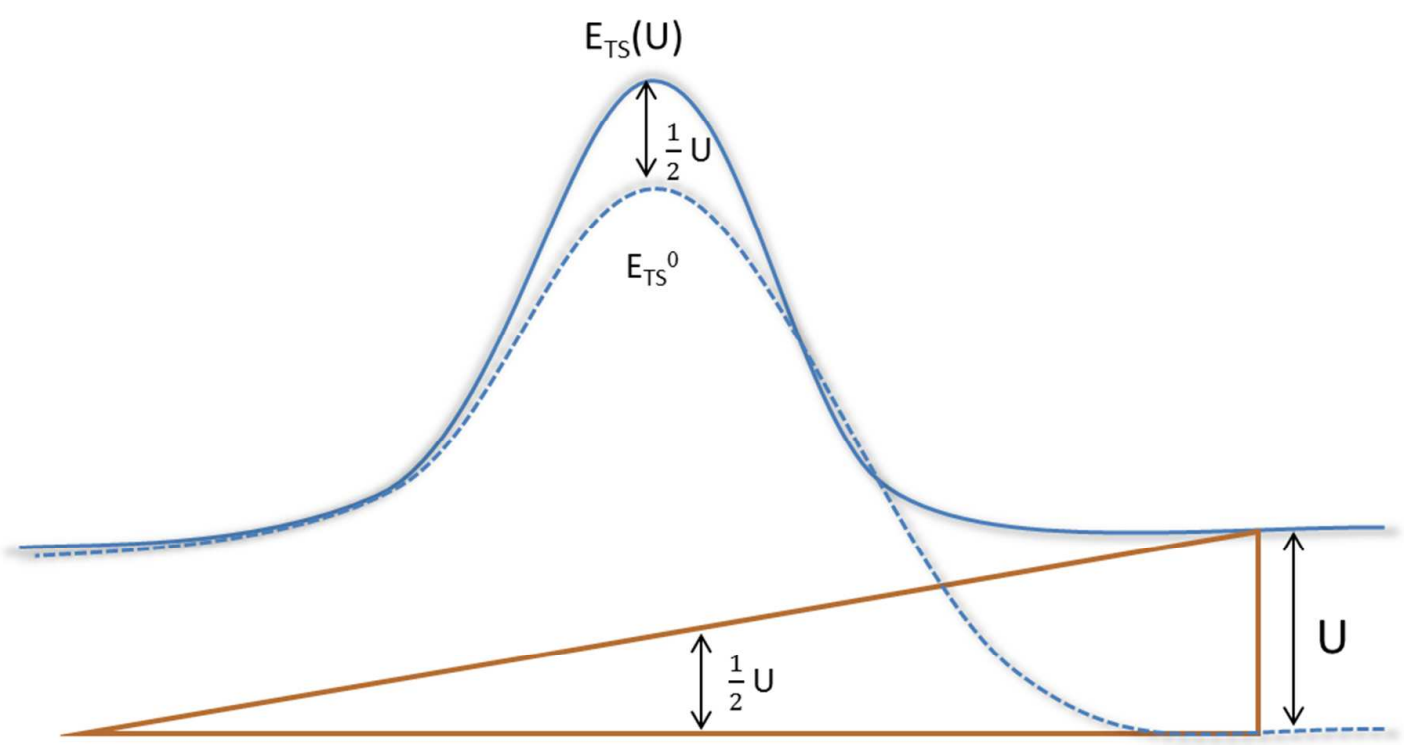

Figure 2. Onset potential, $\mathrm{U}$, is the negative difference between initial and final relaxed energies. $\mathrm{E}_{\mathrm{TS}}{ }^{0}$ is the barrier at zero potential. $\mathrm{E}_{\mathrm{TS}}(\mathrm{U})$ is the potential-dependent barrier where the initial and final energies are equal, since the final energy is offset by $U$. With the assumption of symmetric reactions, effective symmetry factor $(\beta)$ equals 0.5 , since the contribution by $U$ to $E_{T S}(U)$ is exactly $1 / 2 * U$ in the middle of the reaction.

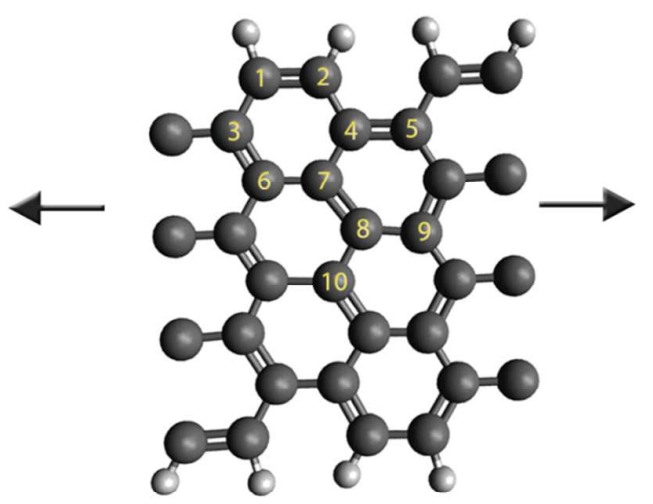

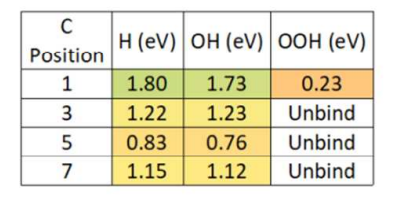

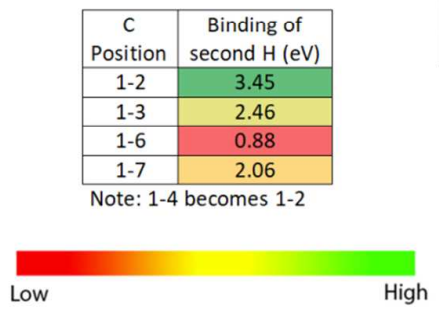

Figure 3. Binding energies of $\mathrm{H}, \mathrm{OH}, \mathrm{OOH}, \mathrm{O}$ and $\mathrm{OO}$ on armchair edge. The arrows indicate the periodic directions. Binding is strongest in site 1,2 at the edges. $\mathrm{OOH}$ does not bind to the basal plane. OO does not bind exothermically in all cases, but the positions are local minima and stable. The preferential site for the second hydrogen to bind is illustrated to show that the second binding energy is stronger than the first, preferring the edged ortho (1-2) site followed by the non-edged ortho (1-3) site. The next most stable is the para sites (1-7). The meta sites are the least favorable, with the site (1-6) is the lowest binding energy $(0.82$ $\mathrm{eV}$ ), and the site $1-4$ becomes site (1-2). The $\mathrm{HOH}$ and $\mathrm{HOOH}$ species do not bind to any sites, even at the edges. 
Figure 4. Binding energies of $\mathrm{H}, \mathrm{OH}, \mathrm{OOH}, \mathrm{OO}$, and $\mathrm{O}$ on zigzag edge. The arrows indicate the periodic directions. Binding is strongest at the edge. The most stable $\mathrm{OO}$ is a 1 -fold bond to the edge position, and it is a triplet. The $\mathrm{HOH}$ and $\mathrm{HOOH}$ species do not bind to any sites, even at the edges. 


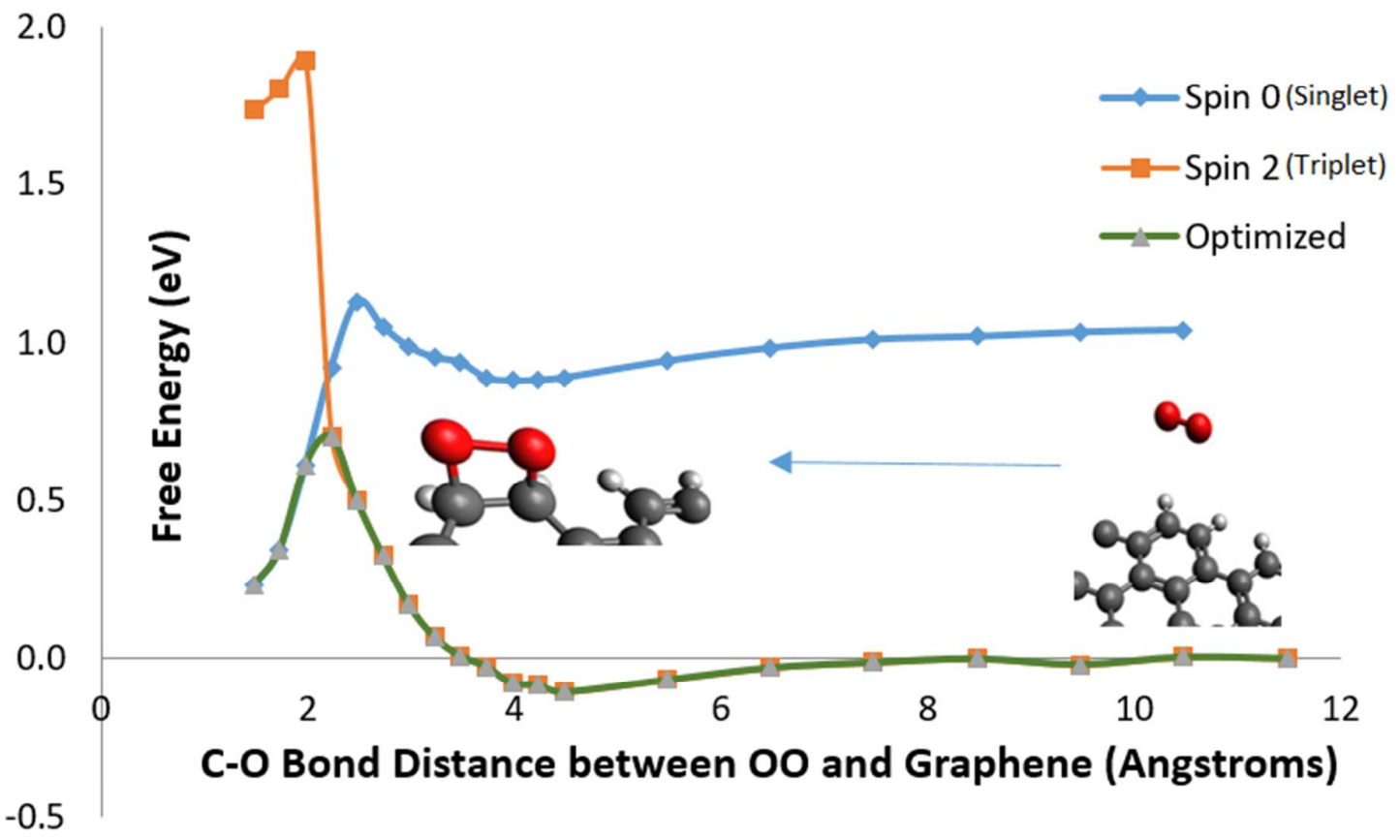

Figure 5. Energy diagram with OO approaching the armchair graphene edge. Optimized line represents the most stable energy between the singlet (Spin 0) and triplet (Spin 2). The optimized barrier is $0.70 \mathrm{eV}$. This barrier was calculated by fixing the $\mathrm{C}-\mathrm{O}$ bond distance and increasing it from a bonded state first by 0.25 Angstroms, then by 1.0 Angstroms until 11 Angstroms. All other atoms are allowed to relax. The plateau for singlet is $\sim 1 \mathrm{eV}$ higher than triplet, which is in agreement with the singlet state of $\mathrm{OO}$ being higher than the triplet state by $\sim 1 \mathrm{eV}$. 


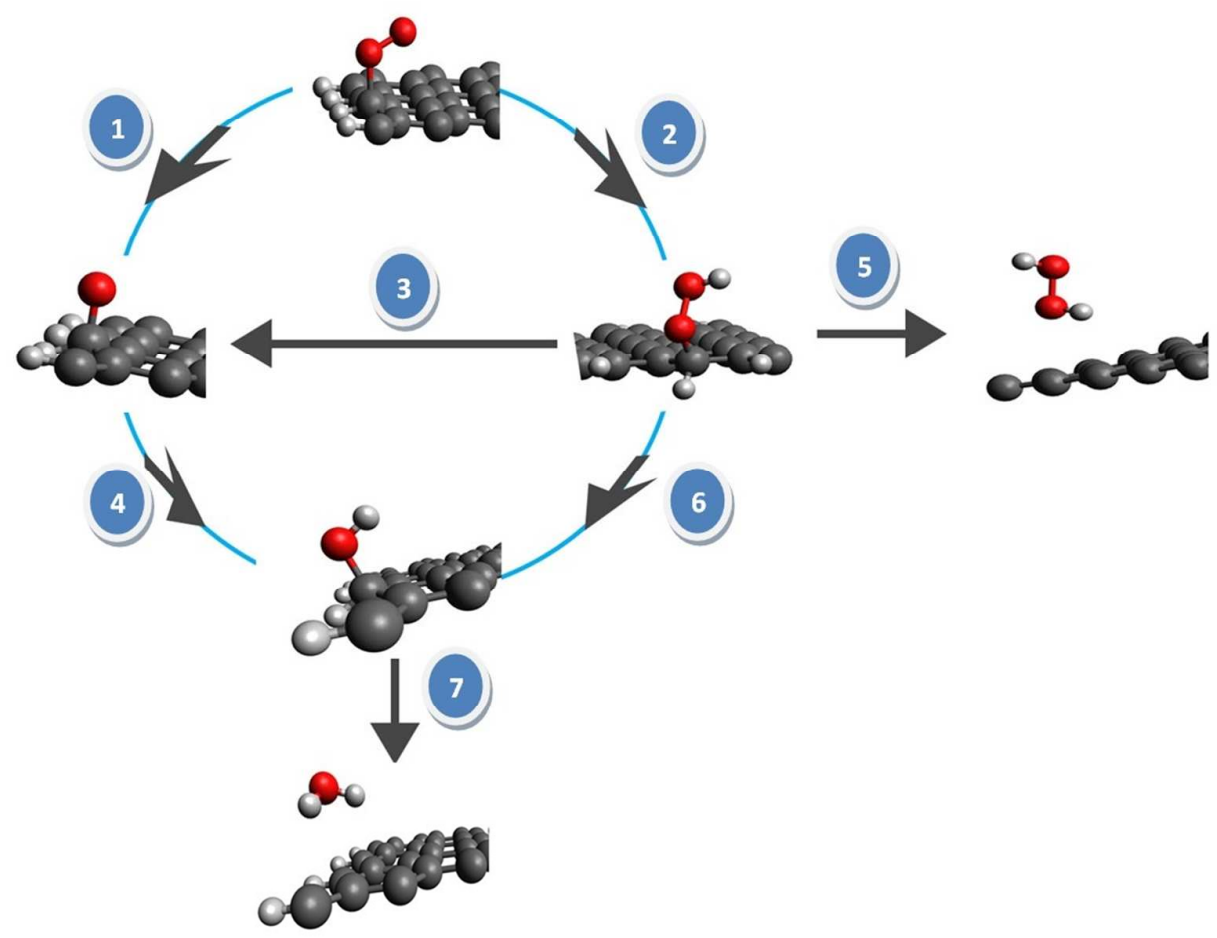

Figure 6. LH mechanistic pathway. There are two possible products -2 electron pathway to create peroxide (product to the right), and 4 electron pathway to create water (bottom product). We find that for the LH mechanism, peroxide was easier to produce for both zigzag and armchair.

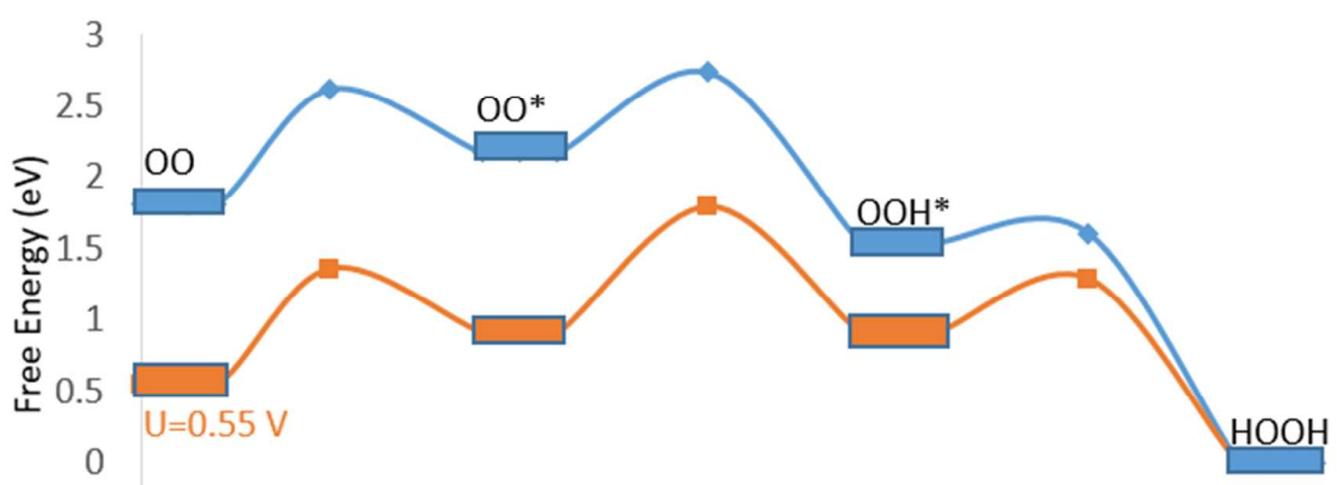

Figure 7. Free-energy diagram for ORR in $2 \mathrm{e}^{-} \mathrm{ER}$ pathway (peroxide formation) at two different potentials with $\beta=0.5$. At the onset potential of $0.55 \mathrm{~V}$ (pH $0 \mathrm{vs.} \mathrm{RHE),} \mathrm{the} \mathrm{highest}$ barrier is $0.94 \mathrm{eV}$ corresponding to the first reduction step, $(\mathrm{OO})_{\mathrm{ad}}+\mathrm{HOH}+\mathrm{e}^{-} \rightarrow(\mathrm{OOH})_{\mathrm{ad}}+$ $\mathrm{OH}^{-}$. 


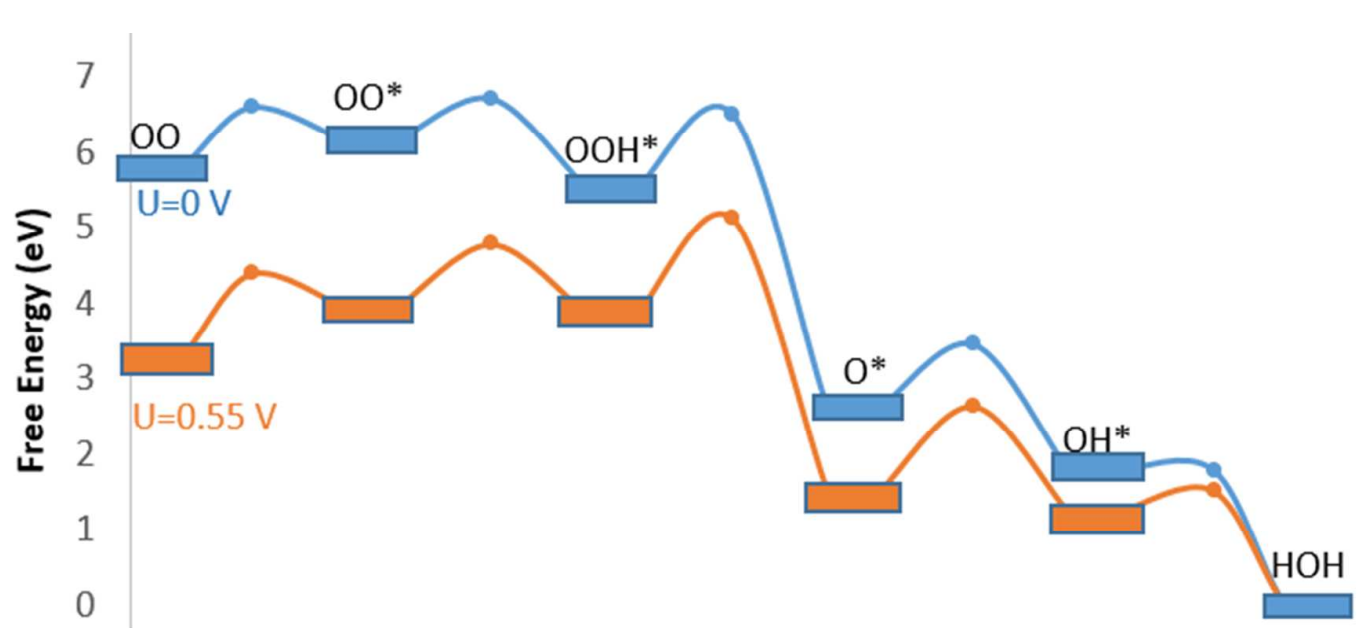

Figure 8. Free-energy diagram for ORR in $4 \mathrm{e}^{-} \mathrm{ER}$ pathway (water formation) at two different potentials with $\beta=0.5$. At the onset potential of $0.55 \mathrm{~V}$ (pH 0 vs. RHE), the highest barrier is $1.46 \mathrm{eV}$ corresponding to the second reduction step, $(\mathrm{OOH})_{\mathrm{ad}}+\mathrm{HOH}+\mathrm{e}^{-} \rightarrow \mathrm{O}_{\mathrm{ad}}+\mathrm{HOH}+$ $\mathrm{OH}^{-}$.
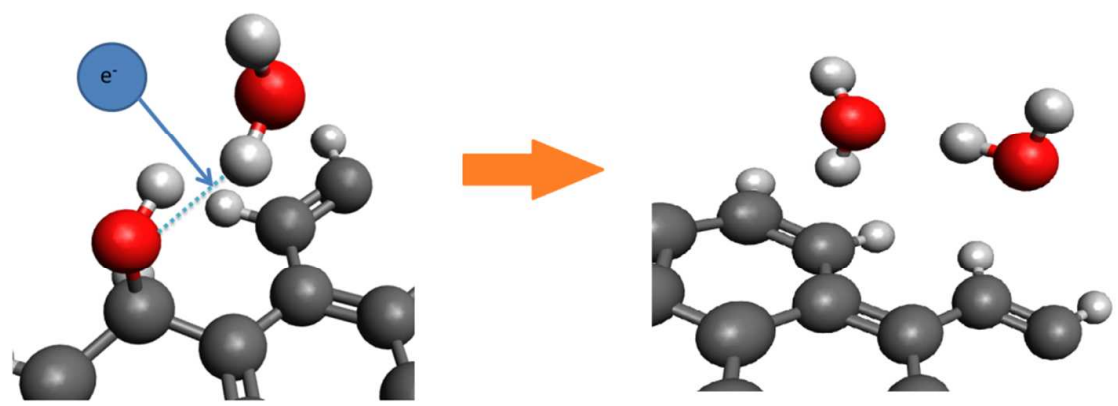

Figure 9. The electron coming from the anode helps establish the bond between $\mathrm{O}$ and $\mathrm{H}$. The bond length relates directly to the bond order.

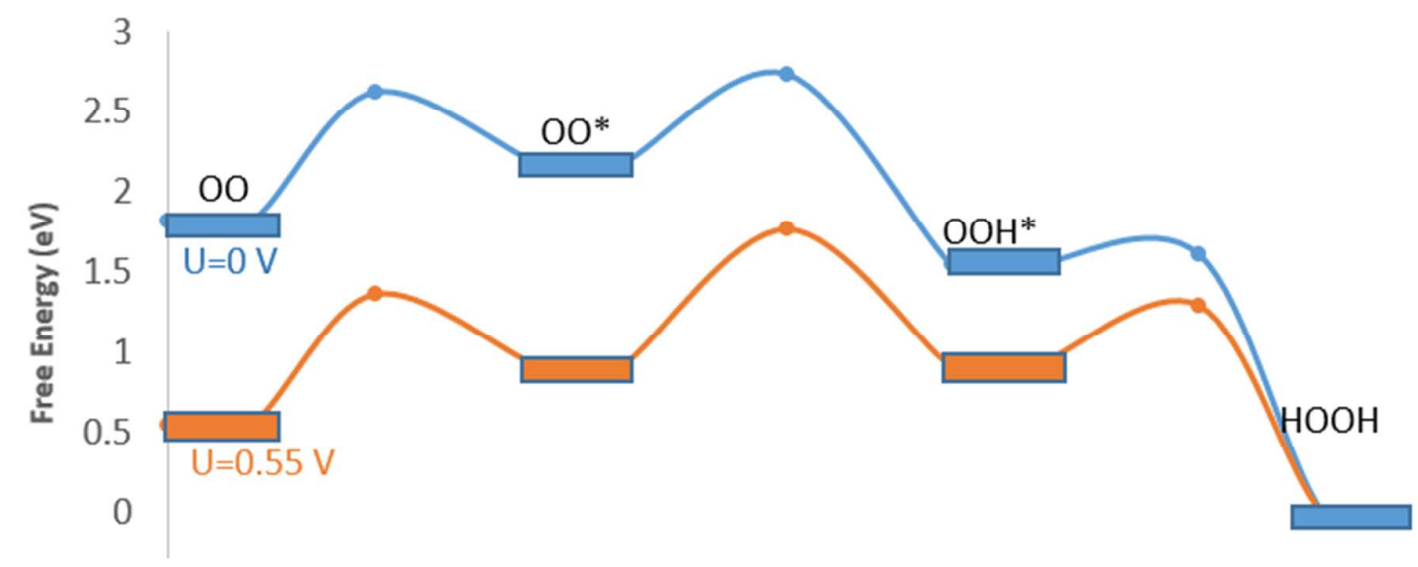

Figure 10. Free-energy diagram for ORR in $2 \mathrm{e}^{-}$pathway (peroxide formation) at two different potentials using bond order for measuring $\beta$. At the onset potential of $0.55 \mathrm{~V}$ ( $\mathrm{pH} 0 \mathrm{vs}$. $\mathrm{RHE}$ ), the highest barrier is $0.92 \mathrm{eV}$ corresponding to the first reduction step, $(\mathrm{OO})_{\mathrm{ad}}+\mathrm{HOH}$ $+\mathrm{e}^{-} \rightarrow(\mathrm{OOH})_{\mathrm{ad}}+\mathrm{OH}^{-}$. The transition state of the RDS corresponds to a $\beta$ of 0.46 . 


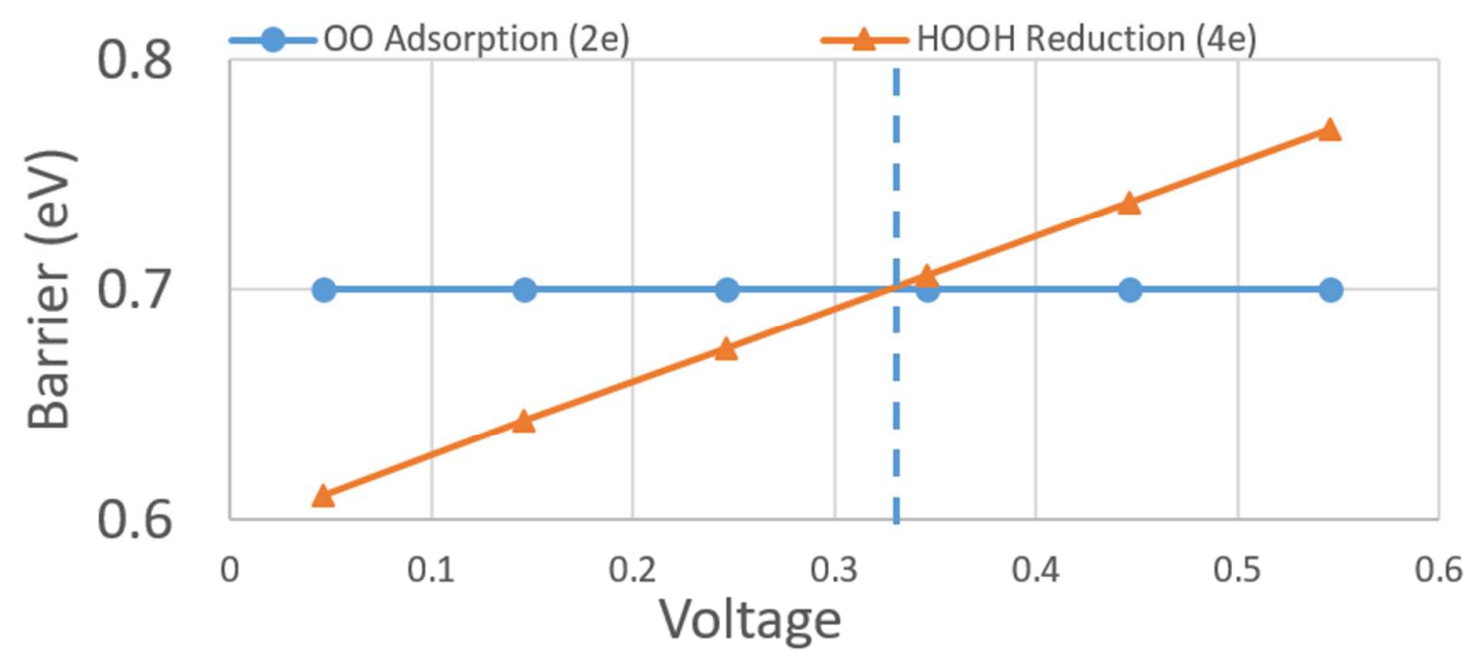

Figure 12. The comparison of barrier of $\mathrm{HOOH}$ Reduction vs. OO Adsorption at different potentials (vs. RHE at $0 \mathrm{pH}$ ). At high potentials, $\mathrm{OO}$ adsorption is favored, while at low potentials $\mathrm{HOOH}$ reduction is favored. Both reactions are competing for the unoccupied armchair site. When only $\mathrm{OO}$ adsorption occurs on an empty site, $2 \mathrm{e}^{-}$ORR occurs. Since the barrier for $\mathrm{HOOH}$ decreases below $0.70 \mathrm{eV}$ at potentials below $0.32 \mathrm{~V}, \mathrm{HOOH}$ reduction occurs, and $4 \mathrm{e}^{-}$ORR forming water becomes energetically favorable. 


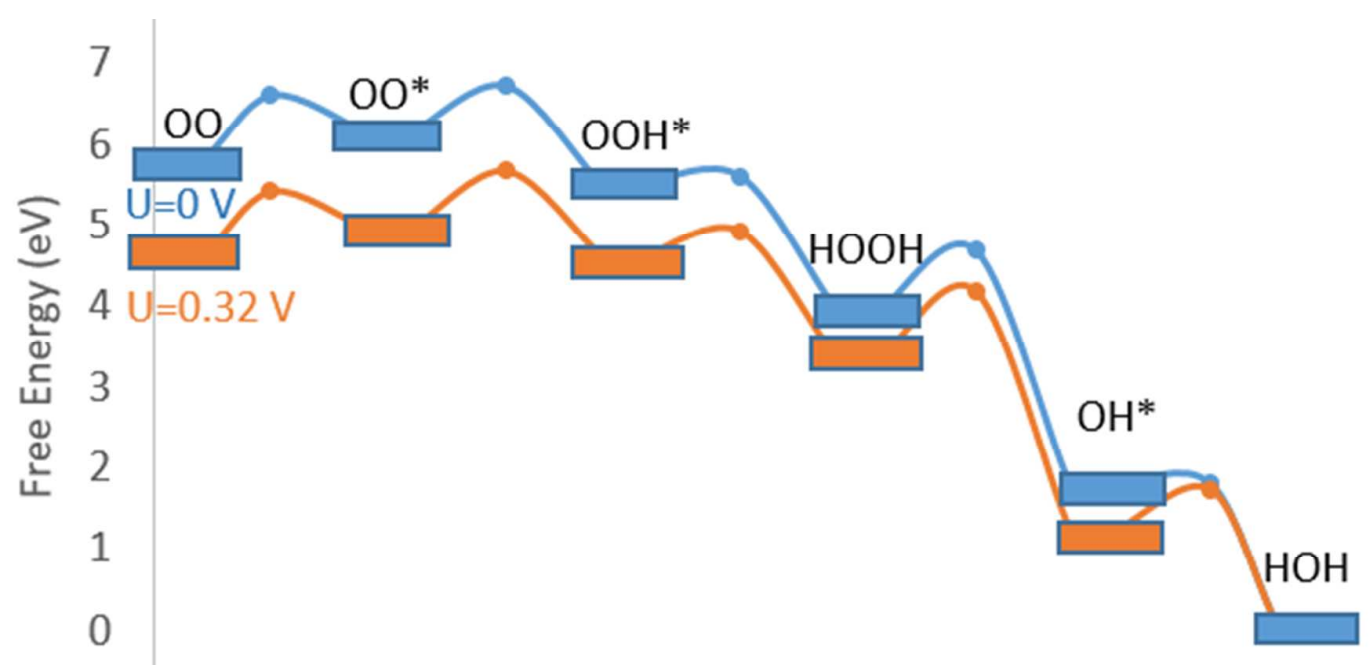

Figure 13. Free-energy diagram for ORR in $4 \mathrm{e}^{-}$pathway (water formation) via peroxide at two different potentials using bond order for measuring $\beta$. At the potential of $0.32 \mathrm{~V}(\mathrm{pH} 0$ vs. RHE), the highest barrier is $0.70 \mathrm{eV}$ corresponding to the reaction, $\mathrm{HOOH}+\mathrm{HOH}+\mathrm{e}^{-} \rightarrow$ $(\mathrm{OH})_{\mathrm{ad}}+\mathrm{HOH}+\mathrm{OH}^{-}$. The transition state of the RDS corresponds to a $\beta$ of 0.46 . 
TOC Graphic:

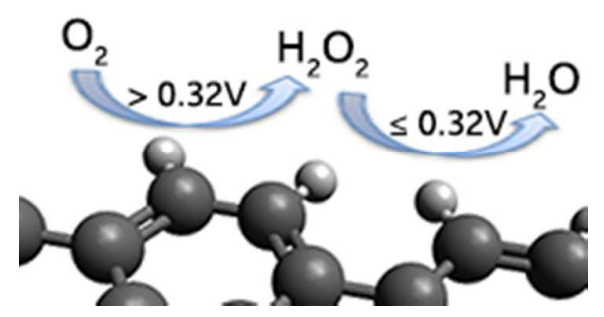

